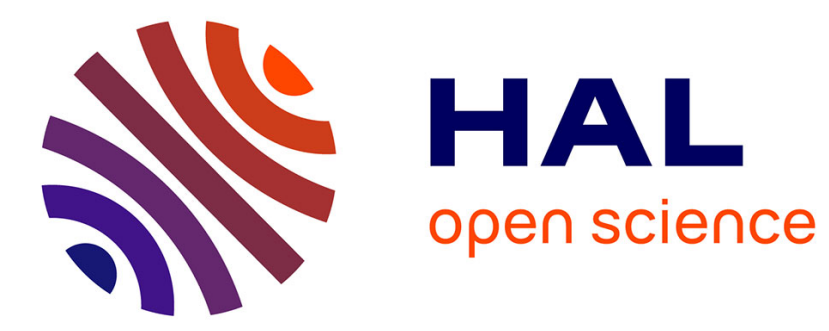

\title{
Escaping Social Pressure: Fixed-Term Contracts in Multi-Establishment Firms
}

\author{
Andrea Bassanini, Eve Caroli, François Fontaine, Antoine Reberioux
}

\section{To cite this version:}

Andrea Bassanini, Eve Caroli, François Fontaine, Antoine Reberioux. Escaping Social Pressure: Fixed-Term Contracts in Multi-Establishment Firms. 2021. hal-03177848

\section{HAL Id: hal-03177848 \\ https://hal.science/hal-03177848}

Preprint submitted on 23 Mar 2021

HAL is a multi-disciplinary open access archive for the deposit and dissemination of scientific research documents, whether they are published or not. The documents may come from teaching and research institutions in France or abroad, or from public or private research centers.
L'archive ouverte pluridisciplinaire HAL, est destinée au dépôt et à la diffusion de documents scientifiques de niveau recherche, publiés ou non, émanant des établissements d'enseignement et de recherche français ou étrangers, des laboratoires publics ou privés. 


\section{Z A Institute of Labor Economics}

Initiated by Deutsche Post Foundation

\section{DISCUSSION PAPER SERIES}

IZA DP No. 14029

\section{Escaping Social Pressure: Fixed-Term Contracts in Multi-Establishment Firms}

Andrea Bassanini

Eve Caroli

François Fontaine

Antoine Reberioux 


\title{
I Z A Institute of Labor Economics
}

Initiated by Deutsche Post Foundation

\section{DISCUSSION PAPER SERIES}

IZA DP No. 14029

\section{Escaping Social Pressure: Fixed-Term Contracts in Multi-Establishment Firms}

\author{
Andrea Bassanini \\ $O E C D$ and IZA
}

Eve Caroli

PSL-University Paris-Dauphine, LEDa and IZA

François Fontaine

Paris School of Economics, University Paris 1 Panthéon-Sorbonne and IZA

\section{Antoine Reberioux}

Université de Paris, LADYSS

Any opinions expressed in this paper are those of the author(s) and not those of IZA. Research published in this series may include views on policy, but IZA takes no institutional policy positions. The IZA research network is committed to the IZA Guiding Principles of Research Integrity.

The IZA Institute of Labor Economics is an independent economic research institute that conducts research in labor economics and offers evidence-based policy advice on labor market issues. Supported by the Deutsche Post Foundation, IZA runs the world's largest network of economists, whose research aims to provide answers to the global labor market challenges of our time. Our key objective is to build bridges between academic research, policymakers and society.

IZA Discussion Papers often represent preliminary work and are circulated to encourage discussion. Citation of such a paper should account for its provisional character. A revised version may be available directly from the author. 


\title{
ABSTRACT
}

\section{Escaping Social Pressure: Fixed-Term Contracts in Multi-Establishment Firms ${ }^{*}$}

We develop a simple theoretical model showing that, by adding to the adjustment costs associated with permanent contracts, local social pressure against dismissals creates an incentive for CEOs to rely on fixed-term contracts, in an attempt to escape social pressure. Using linked employer-employee data, we show that establishments located closer to headquarters have higher shares of fixed-term contracts in hiring than those located further away whenever firms' headquarters are located in self-centered communities and the CEO not only works but also lives there. We show that these findings can only be explained by local social pressure.

JEL Classification: J23, J41, M14, M55, R12

Keywords: social pressure, employment contracts, adjustment costs, CEO reputation

\author{
Corresponding author: \\ Eve Caroli \\ LEDA \\ Université Paris-Dauphine \\ Place du Maréchal de Lattre de Tassigny \\ 75775 Paris, Cedex 16 \\ France \\ E-mail: eve.caroli@dauphine.psl.eu
}

\footnotetext{
* The views expressed here are those of the authors and cannot be attributed to the OECD or its member countries. We are indebted to Matthias Bürker who gave us access to his data on the French 2000 referendum. We are grateful to Omar Bamieh, Giorgio Brunello, Juan Dolado, Gilles Duranton, Cecilia Garcia-Peñalosa, Laurent Gobillon, Andrea Ichino, Saul Lach, Miren Lafourcade, Franck Malherbet, David Margolis, Eric Maurin, Michele Pellizzari, Lorenzo Rocco, Fabiano Schivardi, Elisabeth Tovar, Gregory Verdugo and participants to seminars at the Paris School of Economics, LUISS University, EUI, University of Padua, the OECD, the Aix-Marseille School of Economics, the OFCE as well as to the 2018 Journées Louis-André Gérard Varet and 2018 EALE conference who provided useful comments and suggestions. All remaining errors are ours. We gratefully acknowledge financial support from CEPREMAP (Eve Caroli and François Fontaine), Institut Universitaire de France (François Fontaine) and the French National Research Agency (Grant ANR-19-CE26-0017; Andrea Bassanini, Eve Caroli and Antoine Rebérioux). These institutions were not involved in the study design; in the collection, analysis and interpretation of data; in the writing of the report; nor in the decision to submit the article for publication. Declarations of interest: none.
} 


\section{Introduction}

Fixed-term contracts account for a very large share of new hires in many OECD countries. The literature suggests that whether firms choose to hire workers on temporary rather than permanent contracts depends on the adjustment costs associated with either type of contract. The determinant of the difference in adjustment costs across contracts mostly emphasised in the literature is the gap in legal constraints on terminations: the higher the legal cost of firing workers on permanent contracts as compared to terminating a fixed-term contract, the stronger the incentive for firms to hire temporary workers as a way to reduce adjustment costs (e.g. Boeri and Van Ours, 2013).

However, the share of fixed-term contracts in hiring is large even in countries where legal firing costs are low. For example, in the United Kingdom the share of fixed-term contracts in new hires is as large as $25 \%(\mathrm{OECD}, 2016)$, while the legal cost of firing workers on openended contracts is the third lowest among all OECD countries, after the United States and New Zealand. This suggests that relative adjustment costs on permanent vs fixed-term contracts are not solely determined by legal constraints.

In this paper, we consider another potential determinant of relative adjustment costs, namely social pressure. There is evidence in the literature that social pressure against dismissals creates an incentive for firms to avoid firing workers employed on permanent contracts (Landier, Nair and Wulf, 2009; Bassanini, Brunello and Caroli, 2017). If social pressure increases the relative adjustment costs associated with permanent contract terminations, firms should have a stronger incentive to hire workers on fixed-term contracts. Termination of these contracts is indeed less subject to social pressure because they involve no implicit commitment to long-term employment (Rousseau and Anton, 1988; Charness and Levine, 2000). Moreover, hiring being hardly visible to observers, ${ }^{1}$ employers are unlikely to feel pressure for hiring on permanent rather than fixed-term contracts.

In this paper, we consider the social pressure that local communities put on Chief Executive Officers (CEOs) to avoid dismissals in their immediate surroundings. Social pressure refers to the threat of social sanctions exerted by the local community of the CEO. It has been shown in the literature that individuals want to be liked and respected by others (see e.g. Benabou and Tirole, 2006). Moreover, direct interactions with others have been shown to

\footnotetext{
${ }^{1}$ While news about dismissals loom large in the media (e.g. Friebel and Heinz, 2014), news about hiring usually do not appear on the press. Evidence of this is provided by Heinz and Swinnen (2015) who review articles reporting on downsizing and upsizing in a leading German newspaper over 8 years. On a per-job basis, they find 20 times as many articles reporting on job destruction as articles reporting on job creation.
} 
generate social pressure, thereby affecting individuals' behavior (Della Vigna, List and Malmendier, 2012). This is likely to be the case for CEOs when making human resource management choices, and, in particular, firing decisions. Bandiera et al. (2015) suggest that, beyond profits, CEOs indeed draw utility from non-monetary rewards, including respect from the community. ${ }^{2}$ In this paper, we build on previous evidence showing that CEOs avoid harming their own community by making workers redundant locally, by fear of the social sanction that this could entail, for example through a lack of respect. ${ }^{3}$ We model and test the idea that, in an attempt to escape the social sanction associated with dismissals, firms hire workers on fixedterm rather than permanent contracts.

We first present a simple theoretical model in which employment decisions are taken by the CEO at the firm's headquarters. This assumption is justified by the fact that, in most OECD countries (see OECD, 2013), firing decisions in different plants must be coordinated at the firm level since the threshold that triggers (more expensive) collective redundancy procedures is defined on the basis of the total number of dismissals undertaken in all establishments of the firm. ${ }^{4}$ In our model, whether the CEO decides to hire workers on permanent or fixed-term contracts depends on the probability that the job becomes unproductive and on the relative adjustment costs associated with each type of contract. We allow the difference in adjustment costs across contracts to be affected by the social pressure exerted on the CEO by the local community at the firm's headquarters. The intensity of this pressure depends on the characteristics of the local community. When the community is selfcentered, it cares about dismissals only if they affect the community itself or individuals with whom it is closely connected. To the extent that social interactions decrease with distance, this generates a negative relationship between distance to headquarters and social pressure, and hence a negative relationship between distance and the incentive for firms to hire workers on fixed-term contracts in an attempt to circumvent social pressure. In contrast, when the local community at headquarters is outward-looking, it cares about dismissals wherever they take

\footnotetext{
${ }^{2}$ They report the following statement by a firm owner/manager: "I'd rather be worth 100 million euros (...) and enjoy people's respect when I am the senile chairman of my firm than be worth a billion". The importance of being part of a community is also emphasized by Gianni Agnelli, the former CEO of Fiat: "[The] rooting in a community, in its culture, and in its values is an integral part of the identity of a company. And it leads to incorporating attention and sense of responsibility towards the community, including its problems and its development expectations, in the entrepreneur's behaviour and choices" (Talk given at the Twelfth World Conference FBN in Rome in 2001. Our translation).

${ }^{3}$ See references in the previous paragraph.

${ }^{4}$ The United States and the United Kingdom, where this threshold is defined at the establishment rather than the firm level, are exceptions.
} 
place, which implies that the social pressure perceived by the CEO is the same no matter at which distance firings occur.

Our empirical analysis relies on French data. We match two large datasets. The Déclarations Annuelles des Données Sociales (DADS) contains social security records for all plants and firms in the non-agricultural business sector, including the geographical location of the plants and firms' headquarters. The Déclarations des Mouvements de Main d'Oeuvre (DMMO-EMMO) has quarterly hiring by type of employment contract for all plants with 50 workers or more and a $25 \%$ random sample of those between 10 and 50 workers. By matching these datasets, we obtain information on the geographical dispersion of employment contracts for almost 5,000 multi-establishment firms and over 23,000 plants for the period 1998-2009.

Our empirical analysis takes into account the potential endogeneity of distance to headquarters by instrumenting actual distance with potential distance. The latter is defined as the distance from the headquarters at which the establishment would have been located had its location been chosen only to maximise its contribution to the market potential of the firm (measuring the capacity of the firm to serve large local markets while minimising transport costs).

We provide evidence separately for firms with headquarters located in self-centered and outward-looking communities. Our main measure of self-centeredness is based on the difference in département-level turnout rates between local and national elections. ${ }^{5} \mathrm{We}$ validate this measure by showing that it strongly correlates with a more standard measure of selfcenteredness provided by the European Value Study (EVS, 2010), but available only at a coarser level of aggregation (i.e. administrative regions). We show that, for firms with headquarters located in self-centered communities, the impact of distance to headquarters on the share of fixed-term contracts in hiring is negative and statistically significant. We find no such evidence for firms with headquarters located in outward-looking communities. We then consider the impact of firm visibility at headquarters on the share of fixed-term contracts. The underlying assumption is that CEOs are subject to social pressure arising from their local community only if their firm is visible enough, i.e. represents a large-enough share of local employment in the area of the headquarters. We show that when firms' headquarters are located in self-centered communities, the negative impact of distance on the share of fixed-term contracts is concentrated on firms that are highly visible. We also investigate the role of the CEO's place of living. We expect CEOs to be more sensitive to the social pressure arising from

\footnotetext{
${ }^{5}$ Départements are administrative subdivisions larger than municipalities but smaller than regions.
} 
the community at headquarters when they also live (and not only work) in that community. We show that the negative impact of distance on the share of fixed-term contracts that we observe when firms' headquarters are located in self-centered communities is indeed driven by CEOs who live in that community.

In the light of our model, we interpret these findings as indicating that when social pressure against dismissals is strong, firms tend to hire workers on fixed-term contracts to escape it. We discuss alternative explanations of a negative relationship between distance and the share of fixed-term contracts and we show that none of them can account for the whole set of results that we obtain.

Our paper relates to several strands of literature. The first one is the literature on the choice of labor contracts at the time of hiring. The first generation of theoretical papers on this topic has much emphasised the role of hiring and firing regulations in determining differences in adjustment costs between permanent and temporary contracts. These papers show that employers prefer to hire on temporary contracts whenever legal firing costs are higher than the sum of legal hiring and termination costs for fixed-term contracts (e.g. Blanchard and Landier, 2002; Cahuc and Postel-Vinay, 2002). The most recent literature emphasises the role of other factors - such as differences across jobs in the risk of being hit by a negative shock or in the attractiveness of each type of contract - but these factors would not induce hiring on fixed-term contracts if there were no difference in legal adjustment costs across contracts (e.g. Berton and Garibaldi, 2012; Faccini, 2014; Cahuc, Charlot and Malherbet, 2016). Empirical evidence provides ample confirmation of the role of firing legislation - as well as of effective restrictions on hiring on fixed-term contracts - in determining the distribution of the different types of contract (e.g. Autor, 2003; Kahn, 2010; Centeno and Novo, 2012; Hijzen, Mondauto and Scarpetta, 2017; Bentolila et al., 2012). ${ }^{6}$ We contribute to this literature by showing that firms may resort to fixed-term contracts also in order to escape social pressure against dismissals, which represents an independent explanation from the existence of differences in legal adjustment costs. $^{7}$

\footnotetext{
${ }^{6}$ Recent empirical evidence has also shown that firms resort more to fixed-term contracts when they have a greater risk of job destruction (Dräger and Marx, 2017; Devicienti, Naticchioni and Ricci, 2018).

${ }^{7}$ There is also evidence in the literature that hiring decisions may seem somewhat arbitrary. Hoffman, Kahn and Li (2018) show that managers may discard relevant information about applicants when hiring, which leads to lower quality hires. They interpret this finding as the outcome of managerial biases or errors. Our results suggest that one possible explanation of these biases or apparent errors may be the sensitivity of CEOs (or top managers) to local social pressure.
} 
Our paper also speaks to the literature on social pressure and individual behavior, such as image-motivated altruism. Research in this field suggests that individuals want to be liked and respected and that they seek to gain social approval of their behavior (see Benabou and Tirole, 2006; Andreoni and Petrie, 2004; Ariely, Bracha and Meier, 2009). In fact, behaviors that may seem altruistic are often the result of attempts made by selfish individuals to escape the threat of social sanctions (Della Vigna et al., 2012). This suggests that apparent altruism is partly image-motivated and that individuals are sensitive to the social pressure arising from their immediate social environment. Beyond altruism, there is evidence that social pressure also affects other dimensions of individual behavior, such as civic attitude as regards voting (Gerber, Green and Larimer, 2008; Funk, 2010) or tax compliance (Battiston and Gamba, 2016). Social pressure has also been shown to influence firm behavior. This pressure may be exerted by consumers (e.g. Baron, 2011; Hendel, Lach and Spiegel, 2017). It may also arise from inside the firm. As shown in the literature on corporate governance - e.g. Bertrand and Mullainathan (2003), Giroud and Mueller (2010) and Cronqvist et al. (2009) - when managers are entrenched, they react to social pressure from employees by paying them higher wages than the profitmaximising level. A last strand of literature shows that social pressure may also arise from the local community where the firm headquarters are located. As a reaction, firms tend to concentrate employment reductions, and in particular dismissals, in plants located further away from headquarters - see Landier et al. (2009), Abraham, Goesaert and Konings (2014) and Bassanini et al. (2017). In this paper, we show that firms not only put up with social pressure. They actually implement human resource management strategies to escape it, in particular by hiring employees on fixed-term rather than on permanent contracts.

The rest of the paper is structured as follows. Section I presents a simple model of social pressure and choice of employment contracts. Section II lays out our empirical strategy. Section III describes the data and presents summary statistics. Section IV presents the empirical results. Alternative explanations are discussed in Section V and Section VI concludes.

\section{Social Pressure and Labor Contracts: a Simple Model}

We consider a multi-establishment company where employment decisions are taken at the headquarters. We focus on the choice of employment contracts as the distance to the headquarters increases. We assume, for the sake of simplicity, that in each secondary establishment $j$ each new job $i$ has the same productivity (normalised to 1 ) but a different level 
of risk ${ }^{8}$. Following Cahuc et al. (2016), job risk, denoted by $\gamma>0$, is the probability that at each period the job becomes unproductive and is destroyed. It is drawn, upon recruitment, from a distribution with cumulative distribution function $F_{j}(\gamma)$. It is observed by the firm and is the basis of its contract decision. Finally, we assume that job risks are independent within a given establishment.

Management decisions, including hiring and termination of contracts, are taken by the CEO who works at the headquarters. ${ }^{9}$ We assume that establishments located further away from the headquarters are more difficult to monitor and that CEOs have imperfect information on their local conditions. This heightens the risk of negative productivity shocks leading to job destruction in distant establishments. There is indeed abundant evidence that monitoring problems and asymmetric information induce a positive relationship between the probability of downsizing and the distance to the headquarters (see e.g. Landier et al., 2009, Giroud, 2013, Kalnins and Lafontaine, 2013, and Charnoz, Lelarge and Trevien, 2018). As a consequence, we assume that job risk increases with the distance $\delta$ between the establishment and the firm's headquarters ${ }^{10}-$ i.e. the distribution of $\gamma$ shifts upward:

$$
\frac{\partial F_{j}(\gamma)}{\partial \delta_{j}}=\frac{\partial F\left(\gamma, \delta_{j}\right)}{\partial \delta_{j}}<0
$$

When meeting with a worker, the CEO has to decide whether or not to hire his/her and the type of contract to be chosen between two alternatives: a permanent contract and a fixedterm contract of duration $D .{ }^{11}$ Writing a contract induces a strictly positive cost, $h^{o}$ or $h^{f}$, for permanent or fixed-term contracts, respectively. Employees on permanent contracts can be dismissed by paying a legal firing cost $d^{o}$. No legal cost is associated with termination of fixedterm contracts. By law, however, it is impossible to fire a worker before the end of a fixed-term contract. $^{12}$

Near each establishment and the headquarters lives a community. Following Akerlof (1980), we assume that the CEO cares about profits and his/her reputation. A community can

\footnotetext{
${ }^{8}$ Taking into account productive heterogeneity would not change our predictions.

${ }^{9}$ Our assumption is that employment decisions are taken centrally at headquarters. For the sake of simplicity, we represent these decisions as taken by the CEO even if, in practice, they may also be taken by other top executives.

${ }^{10}$ We do not model here why a firm has at least one plant beyond the headquarters, and why plants may be located at different distances from headquarters.

${ }^{11}$ We assume here that there is a unique possible duration $D$ defined by the law. In many countries the maximum duration of fixed-term contracts, including possible renewals, is indeed fixed by the law (see e.g. OECD, 2014).

${ }^{12}$ Cahuc et al. (2016) make the same assumption, which corresponds to the French legislation in which a fixedterm contract cannot be breached. However, lifting this assumption would not change the results provided that there are positive hiring costs at least for fixed-term contracts.
} 
sanction the CEO when he or she is perceived as harming it. Sanctions take the form of a reduction in the CEO's reputation within the community. We also assume that CEOs are sensitive only to social sanctions taking place in their local environment, i.e. in the area of the headquarters. ${ }^{13}$

The CEO's intertemporal utility from a job $i$ in establishment $j$ is the sum of the expected instantaneous profits minus contracting and legal costs as well as social sanctions undergone in the case of dismissal. We assume that hiring on (or termination of) fixed-term contracts does not entail any social sanction. Social sanctions indeed result both from (i) the refusal of the CEO's behavior by the community and (ii) the visibility of this behavior since a behavior cannot be disapproved if it is unknown to the community. The choice to hire workers on fixed-term contracts is unlikely to be visible to the community since the literature provides evidence that job creations themselves are hardly visible. Heinz and Swinnen (2015) review articles reporting on downsizing and upsizing in a leading German newspaper over 8 years. On a per-job basis, they find 20 times as many articles reporting on job destruction as articles reporting on job creation. Similarly, Bassanini et al (2020) study the reactions on Twitter to large-scale jobdestruction and job-creation events announced on the UK press. They find that negative reactions to job-destruction announcements are much more numerous and fiercer than the positive reactions to job-creation announcements. These findings suggest that job creations go largely unnoticed and, a fortiori, the type of employment contracts on which employees are hired. Therefore, local communities do not have the relevant information that would allow them exerting significant social pressure against hiring on fixed-term contracts. As regards the termination of fixed-term contracts, it is unlikely to trigger strong disapproval from the community even when noticed since, as argued in the literature (see Rousseau and Anton, 1988; Charness and Levine, 2000), terminations are considered unfair only in case of commitment to long-term employment, which does not hold for fixed-term contracts. In any case, what we make here is only a simplifying assumption and the main predictions of the model still hold if communities impose a social sanction on CEOs in the case of hiring on (or termination of) fixed-term contracts, as long as it remains smaller than in the case of dismissals - see Appendix A.1.4.

Social sanctions occur if the dismissal is perceived as harmful by the community of the headquarters. Because this perception is not necessarily the same if a dismissal takes place within the community itself or at a more distant place, we allow the level of social sanction

\footnotetext{
${ }^{13}$ Bassanini et al. (2017) provide evidence that this assumption holds in French data.
} 
(denoted $S_{j}$ ) to depend on the distance to the firm's headquarters. The relationship between distance and social sanctions by the headquarters' community is likely to vary with how much a community cares about dismissals of other people. In the model, we consider two types of communities, self-centered and outward-looking. Self-centered communities care only about shocks (incl. dismissals) affecting their members or other communities with which they interact. There may be two reasons for this pattern of preferences: either members of the community care about what happens to co-members because this directly enters their utility function as an argument (they are to some extent altruistic towards their co-members) or because this has an impact on a variable affecting their own utility (they are selfish but the fate of their co-members impacts one of the arguments of their utility function). Whatever the mechanism at work, the more intense the interactions between individuals living at headquarters and individuals living in another community, the greater the social sanctions imposed on the CEO in the case of dismissals of members of this other community. In other words, in selfcentered communities, the social sanction implied by a dismissal in establishment $j$ is an increasing function of the intensity of the interactions between the community where the job is destroyed and the community where the firm's headquarters are located. To the extent that social interactions decrease with geographical distance, ${ }^{14} S_{j}$ will be a decreasing function of distance from headquarters $\delta_{j}$ :

$$
S_{j}=s-m\left(\delta_{j}\right)
$$

where $s$ is a constant and $m$ is a monotonic increasing function. By contrast, outward-looking communities equally care about all shocks, wherever they take place. Therefore, they are equally concerned about dismissals, no matter where destroyed jobs are located, that is:

$$
S_{j}=s \quad \forall j
$$

In the following, we drop the establishment subscript to simplify the notation. Firms are wage-takers and workers are paid wage $w .{ }^{15}$ Assuming away discounting for simplicity, the

\footnotetext{
${ }^{14}$ Evidence that social relations decrease with geographical distance between individuals is provided by the Contact entre les personnes ("Contact between people") Survey, carried out by the French Statistical Institute (INSEE) in 1983. This survey has information on the frequency of encounters of an individual with his/her friends, children, parents and in-laws and the distance at which these relatives and friends live, for 17,797 couples of individuals. For distances higher than $5 \mathrm{~km}$, the coefficient of correlation between distance and the frequency of encounters is -0.05 - significant at the $1 \%$ level.

${ }^{15}$ For the sake of simplicity, we assume that wages and productivities do not depend on the type of contract. Because this would just create differences in per-period profits, it would not change the effect of distance on the choice of employment contract.
} 
CEO's expected utility from hiring on a permanent contract for a job with risk $\gamma$ in a given establishment is:

$$
U^{o}(\gamma)=\sum_{k=0}^{\infty}\left[(1-\gamma)^{k}(1-w)\right]-h^{o}-\sum_{k=0}^{\infty}(1-\gamma)^{k} \gamma\left(S+d^{o}\right)
$$

The first two terms on the right-hand side stand for expected profits over the duration of the job, that is the sum of expected instantaneous profits, multiplied by the probability of job survival at time $k$, minus the contract writing cost $h^{o}$. The last term stands for the cost of separation that is the legal costs and the social sanction. ${ }^{16}$ Re-arranging equation [1.4] yields:

$$
U^{o}(\gamma)=\frac{(1-w)}{\gamma}-c^{0}
$$

where $c^{0}=d^{o}+S+h^{o}$. Social sanctions can be seen, therefore, as an additional adjustment cost beyond hiring costs and legal firing costs. By contrast, as discussed above, since fixedterm contracts are expected to terminate after a time $\operatorname{span} D$, their termination involves no social sanction. The CEO's expected utility from hiring on a fixed-term contract is:

$$
U^{f}(\gamma)=\sum_{k=0}^{D-1}(1-\gamma)^{k}-w D-h^{f}=\frac{1-(1-\gamma)^{D}-\gamma w D}{\gamma}-h^{f}
$$

In words, the expected utility that the CEO derives from a fixed-term contract is the difference between the expected output over the duration of the contract, and the sum of the wage bill paid during the whole contract $(w D)$ and the contract writing cost $h^{f}$.

The firm chooses a permanent contract if $U^{o}(\gamma) \geq U^{f}(\gamma)$ as long as $U^{o}(\gamma) \geq 0$, and a fixed-term contract if $U^{o}(\gamma)<U^{f}(\gamma)$ as long as $U^{f}(\gamma) \geq 0$. As shown in Appendix A.1.1, both expected utilities in equations [1.5] and [1.6] are decreasing and convex in $\gamma$. We assume that when $\gamma=1$ (that is, the job ends with probability one at the end of the first period), the fixed-term contract is the one yielding the greatest utility, even if this can be negative. ${ }^{17}$ Under this assumption, the difference in intertemporal utility $U^{o}(\gamma)-U^{f}(\gamma)$ is decreasing with the job risk and there is a unique job risk threshold, denoted $\bar{\gamma}$ hereafter, such that the firm hires on permanent contracts if $\gamma<\bar{\gamma}$ (see Appendix A.1.2). Intuitively, when the job risk tends to 0 , the value of a permanent contract tends to infinity, while it goes to a finite value in the case of

\footnotetext{
${ }^{16}$ We thus assume that production is separable which is consistent with the fact that job risk on a given job is assumed to be independent from that of other jobs.

${ }^{17}$ This is equivalent to assuming $1-w D-h^{f}>1-w-c^{o}$. If this were not the case, the choice problem would be trivial: permanent contracts would be more attractive for the CEO for any value of $\gamma$, since - as shown in Appendix A.1.1 - expected utilities in equations [1.5] and [1.6] are decreasing and convex in $\gamma$ and when $\gamma \rightarrow 0$, $U^{o}(\gamma) \rightarrow+\infty$, while this is not the case for $U^{f}(\gamma)$.
} 
fixed-term contracts because job duration is fixed. Moreover, both values decrease with job risk, but less so for fixed-term contracts since at the end date they can be terminated at no cost - see Figure 1.

We consider now how contract choices are affected by the adjustment costs. An increase in adjustment costs on permanent contracts $c^{o}$ reduces the contract-choice threshold $\bar{\gamma}$, that is:

$$
\frac{d \bar{\gamma}}{d c^{o}}<0
$$

The formal proof is provided in Appendix A.1.3 but it can be easily understood since an increase in adjustment costs for permanent contracts makes these contracts more expensive for any job risk $\gamma$, thereby making them less convenient. Graphically, the expected-utility curve for permanent contracts shifts downwards while changes in $c^{o}$ do not affect the corresponding curve for fixed-term contracts, thereby resulting in a shift to the left of the cut-off point.

Let us assume that if $\gamma=1$ fixed-term contracts always yield a non-negative expected utility (we relax this assumption in Appendix A.1.5). In this case, the share of permanent contracts in new hires is simply $L^{o}=F(\bar{\gamma}, \delta)$ and that of fixed-term contracts is $L^{f}=1-L^{o}$. If adjustment costs on permanent contracts increase, the job-risk cut-off goes down and so does the probability of hiring on a permanent contract. In turn, this raises the share of fixed-term contracts in new hires:

$$
\frac{d L^{f}}{d c^{o}}=-f(\bar{\gamma}, \delta) \frac{d \bar{\gamma}}{d c^{o}}>0
$$

where $f$ stands for the density function of job risk $\gamma$. Since $c^{o}=h^{o}+d^{o}+S$, we have that $d \bar{\gamma} / d S=d \bar{\gamma} / d c^{o}$, which implies that potential social sanctions, which would occur in the case of dismissals of workers on permanent contracts, have an impact on hiring decisions in terms of contract choice:

$$
\frac{d L^{f}}{d S}=-f(\bar{\gamma}, \delta) \frac{d \bar{\gamma}}{d c^{o}}>0
$$

In other words, the CEO tries to escape the threat of social sanctions - i.e. social pressure against dismissals - by reducing hiring on permanent contracts and resorting to fixed-term contracts, instead.

Because of imperfect information and monitoring problems, distant jobs are riskier (see equation [1.1] above), which tends to increase the share of fixed-term contracts in establishments that are located far away from the headquarters. However, because social 
sanctions can also change with distance, the overall relationship between the share of fixedterm contracts $L^{f}$ and distance to headquarters is complex. The total derivative of the share of fixed-term contracts with respect to distance reads:

$$
\frac{d L^{f}}{d \delta}=-f(\bar{\gamma}, \delta) \frac{d \bar{\gamma}}{d S} \frac{d S}{d \delta}-\frac{\partial F(\gamma, \delta)}{\partial \delta}
$$

When the headquarters are located in an outward-looking community, social sanctions are independent of distance $(d S / d \delta=0)$ and the first term on the right-hand side of eq [1.7] is zero: the only effect of distance is the one occurring through monitoring and imperfect information, that is (see equation [1.1] above):

$$
\frac{d L^{f}}{d \delta}=-\frac{\partial F(\gamma, \delta)}{\partial \delta}>0
$$

which implies that the share of fixed-term contracts rises with distance when headquarters are located in outward-looking communities. In contrast, in self-centered communities, social sanctions induced by separations decrease with distance to the headquarters $(d S / d \delta<0)$. In this case, while the second term on the right-hand side is positive, the first one is negative, which results in an ambiguous sign of $d L^{f} / d \delta$. In other words, when the headquarters are located in a self-centered community, the threat of social sanctions counteracts the effect of monitoring and imperfect information. If the effect of social pressure against dismissals is large enough, the share of fixed-term contracts may even decline with distance.

So far, we have assumed that the firm is large enough so that the actions of the CEO are visible in the local community of the headquarters. If, in contrast, the firm is too small to be visible, equation [1.2] becomes:

$$
S_{j}=0
$$

and is therefore a special case of [1.3]. In this case, inequality [1.8] holds whether the local community at headquarters is self-centered or outward looking.

To sum up, our model shows that the threat of social sanctions by the local community - i.e. social pressure - may generate a negative relationship between distance to headquarters and the share of fixed-term contracts in new hires, when headquarters are located in areas characterised by self-centered communities. By contrast, when the headquarters are located in areas characterised by outward-looking communities, social pressure does not vary with distance: the share of fixed-term contracts in new hires is then larger in distant establishments because they are more difficult to monitor and imperfect information on their local conditions 
increases the risk of negative shocks. The empirical validity of these predictions is investigated in the remainder of this paper.

\section{The Econometric Model}

\subsection{Distance to Headquarters, Self-centeredness and Short-term Contracts}

To investigate the role of social pressure on firms' hiring behavior, we estimate the following equation:

$$
L^{f}{ }_{j H t}=\beta_{0}+\beta_{1} D_{i s t_{j H t}}+X_{j H t} \beta_{2}+E A_{j H}+D_{t}+D_{H}+\varepsilon_{j H t}
$$

where $L^{f}{ }_{j H t}$ denotes the share of fixed-term contracts in new hires in establishment $j$ of a firm with headquarters $H$ at year $t, D_{i s t} t_{j H}$ is the distance of establishment $j$ to the firm's headquarters at year $t$ and $X_{j H t}$ is a vector of establishment-level controls. $E A_{j H}$ is a dummy variable for the employment area ${ }^{18}$ in which establishment $j$ is located, $D_{t}$ and $D_{H}$ are year and headquarters dummies, respectively, and $\varepsilon_{j H t}$ is an error term. By including both headquarters and employment-area fixed effects, we control for geographical characteristics of establishments and headquarters.

We estimate this equation on our full sample of firms and separately for firms with headquarters located in self-centered and outward-looking communities. Based on our model, we expect distance to headquarters to have a positive impact on the share of fixed-term contracts when headquarters are located in outward-looking communities since the (positive) effect of monitoring and asymmetric information is not counterbalanced by the effect of social pressure. In contrast, when headquarters are located in areas where local communities are self-centered, the overall effect of distance on the share of fixed-term contracts may be negative if the impact of social pressure is strong enough. On the full sample of firms, the effect of distance is ambiguous.

We estimate equation [2.1] on secondary establishments only and hence exclude headquarters from our sample. The latter are indeed, by definition, at zero distance from themselves and are functionally different from secondary establishments so that they may have lower shares of fixed-term contracts.

\footnotetext{
${ }^{18}$ Employment areas are travel-to-work zones defined on the basis of daily commuting patterns as observed at the beginning of the 1990s. Employment areas correspond to local labor markets and usually contain a city and its catchment area. There are 341 such areas in mainland France with an average size of $1,570 \mathrm{~km}^{2}$.
} 
Distance to headquarters, however, is likely to be endogenous. For example, because monitoring establishments located further away from headquarters is more difficult, firms will open and keep such establishments only if they have productive advantages that compensate monitoring costs. If performance is also correlated with the type of employment contracts, OLS estimates of [2.1] are likely to be biased. To address the potential endogeneity of distance, we rely on an instrumental variable (IV) strategy.

Following Bassanini et al. (2017), we instrument the distance between one establishment and its headquarters by the potential distance defined as the distance between the headquarters and the place where the establishment would have been located (its potential location) had this location been chosen only to maximise its contribution to the firm market potential (irrespective of other plant characteristics).

In economic geography, the market potential is a measure of the relative advantage of a location in terms of access to final demand (see Harris, 1954). It is defined as the sum of the purchasing capacities of surrounding local markets weighted by the inverse of their distance which typically proxies transportation costs to customers. By analogy, we define the market potential of a multi-establishment firm $F$ as:

$$
M P F_{F}=\sum_{k} \frac{P C_{k}}{\min _{j \in F}\left\{\text { Dist }_{k j}\right\}}
$$

where $P C_{k}$ stands for the purchasing capacity of local market $k$ and $j$ indexes the establishments of the firm, including the headquarters. In other words, the market potential of firm $F$ is the sum of the purchasing capacities of each local market weighted by the inverse of the distance (Dist) of these markets to the closest establishment of the firm. As is classical, we capture purchasing capacity by current population ${ }^{19}$ and local markets by French employment areas.

Let $K_{j}$ denote the set of local markets for which $j$ is the closest establishment among all establishments of firm $F$, i.e. for which $D i s t_{k j}<\min _{i \in F \backslash\{j\}}\left(D i s t_{k i}\right)$ where $F \backslash\{j\}$ is the set of all establishments of firm $F$ excluding $j$. Then, market potential $M P F$ can be rewritten as:

\footnotetext{
${ }^{19}$ In the economic geography literature, purchasing capacity is proxied either with income-based measures (see e.g. Combes, Mayer and Thisse, 2008) or with population-based measures (see e.g. Bottazzi and Peri, 2003; Ioannides and Overman, 2004 and Briant, Combes and Lafourcade, 2010). We use a population-based measure insofar as information on aggregate income is not available at the level of employment areas.
} 


$$
M P F_{F}=\sum_{j \in F} \underbrace{\sum_{k \in K_{j}} \frac{P O P_{k}}{D i s t_{k j}}}_{C M P F_{j}}
$$

where $P O P$ denotes population. $C M P F_{j}$ can be interpreted as the contribution of establishment $j$ to the market potential of firm $F$. It can be seen as a proxy of the relative size of the local demand served by each establishment of $F$.

Once the contribution to the firm market potential is defined in this way, for each establishment of each firm in our sample, we identify the employment area where this establishment should have been located to maximise its contribution to the firm market potential. We call it the potential location of the establishment. ${ }^{20}$ Formally, the potential location of establishment $j\left(P L_{j}\right)$ is defined as:

$$
P L_{j}=\underset{h}{\operatorname{argmax}}\left\{C M P F_{h}\right\}=\underset{h}{\operatorname{argmax}}\left\{\sum_{k \in\left\{\text { Dist }_{k h}<\min _{i \in F \backslash j j\}}\left(\text { Dist }_{k i}\right)\right\}} \frac{P O P_{k}}{\text { Dist }_{k h}}\right\}
$$

where $h$ indexes the employment areas. One concern here could be that the population we use to compute $C M P F$ is not pre-dated with respect to our sample. To overcome this problem, as suggested by the literature in economic geography, we use local terrain ruggedness as an exogenous predictor of local population. ${ }^{21}$ The underlying assumption is that more rugged locations are less inviting so that fewer individuals settle there. Taking the maximum value of ruggedness in our data minus the effective ruggedness of the area as an exogenous proxy of population, ${ }^{22} P L_{j}$ can be written as:

$$
P L_{j}=\underset{h}{\operatorname{argmax}}\left\{\sum_{k \in\left\{D i s t_{k h}<\operatorname{mi}_{i \in F \backslash j j\}}\left(D_{i s t}\right)\right\}} \frac{R U G_{\max }-R U G_{k}}{\text { Dist }_{k h}}\right\}
$$

\footnotetext{
${ }^{20}$ In practice, for each firm in our sample, we pick up one of its secondary establishments and remove it. We then consider each employment area in France and consider what would be the contribution to the firm market potential if an additional plant were located there. We take the employment area that maximises this contribution: this is the potential location. In doing so, we consider all the establishments of firm $F$ in France (see col. (2) of Table A6) and not only the establishments belonging to our regression sample. For the computation, we assume that all establishments of $F$ are located at the barycentre of their region. This simplifying assumption allows us to save substantial computational time, since some of our firms have hundreds of establishments.

${ }^{21}$ See Combes et al. (2010) and Nunn and Puga (2012).

${ }^{22}$ Following Combes et al. (2010), local terrain ruggedness is defined here as the mode of maximum altitudes across all pixels in an employment area minus the mode of minimum altitudes, using pixels of $1 \mathrm{~km} \mathrm{by} 1 \mathrm{~km}$. The correlation between ruggedness and population across employment areas is significant at the $1 \%$ level in our data.
} 
where $R U G_{k}$ denotes ruggedness of the employment area $k$ and $R U G_{\text {max }}$ is the maximum ruggedness over all employment areas. We then compute the distance between the potential location and the location of the firm's headquarters, which we call potential distance.

To qualify as a valid instrument, potential distance must affect the share of fixed-term contracts in hiring only through actual distance, and should therefore be unrelated with any unobserved plant-specific characteristics that can affect fixed-term contracts after conditioning on actual distance. Given that the potential location has been constructed only using information on local demand, the only reasons why potential distance may affect the share of fixed-term contracts is either through actual distance or because it could be correlated with local demand. Yet, as shown in Table A1, potential distance is uncorrelated to local demand, as measured by the $C M P F{ }^{23}$ This suggests that the orthogonality condition required for instrument validity holds for the potential distance. ${ }^{24}$

Finally, given that our instrument is based on final demand, the compliers are multiestablishment companies producing for the final market, rather than intermediate-good or service producers. This could, in principle, make our instrument weak. As evidenced in Section $\mathrm{IV}$, this is not the case.

\subsection{Firm visibility and CEOs' place of living}

The literature on social pressure suggests that it affects individuals' decisions only when they are visible (Della Vigna et al., 2012; Gerber et al., 2008; Funk, 2010). In our setup, this suggests that CEOs will be subject to social pressure against dismissals arising from the local community of their headquarters only when their firm is visible in that community. We test this prediction by estimating the following equation:

$L^{f}{ }_{j H t}=\beta_{0}+\beta_{1} D_{i s t_{j H t}} * H V_{H t}+\beta_{2}$ Dist $_{j H t} * L V_{H t}+X_{j H t} \beta_{3}+E A_{j H}+D_{t}+D_{H}+\varepsilon_{j H t}$

where $H V_{H t}$ is a dummy variable capturing the fact that the firm is highly visible in the employment area of its headquarters and $L V_{H t}$ is a dummy variable capturing low visibility of

\footnotetext{
${ }^{23}$ In contrast, the actual distance to headquarters turns out to be positively correlated with $C M P F$ : the coefficient of correlation is as high as 0.15 and significant at the $1 \%$ level - see Appendix Table A1. This suggests that establishments located far away from their headquarters are selected on their contribution to the firm's market potential. As a consequence, OLS estimates of equation [2.1] are likely to be biased.

${ }^{24}$ An alternative would be to construct potential distance replacing $P O P_{k}$ by an arbitrary constant in equation [2.2]. This instrument would be orthogonal by construction. When local demand is uniformly distributed, firms indeed maximise their market potential by locating establishments so that their contribution to the market potential is equal. This implies that potential distance is uncorrelated with the $C M P F$ in the potential location and hence with the $C M P F$ in the actual location. As shown in Appendix Table A9, our results are robust to using this instrument although it is not our preferred one since it contains less information.
} 
the firm at headquarters. Since visibility is likely to be correlated with firm size, we control for the interactions between distance to headquarters and a set of dummies of firm size (both in the whole country and in the employment area of the headquarters). We expect $\beta_{2}$ to be positive: the impact of distance to headquarters on the share of fixed-term contracts should be positive when the firm is hardly visible at headquarters since, in this case, the social pressure effect is expected to be negligible and the monitoring/asymmetric information effect should dominate. In contrast, when the firm is highly visible at headquarters, the impact of distance (i.e. $\beta_{1}$ ) is ambiguous since the positive impact due to monitoring or asymmetric information will be counterbalanced by the negative impact of social pressure.

We estimate equation [2.3] both on our full sample and separately on firms with headquarters located in self-centered and outward-looking communities. When the firms' headquarters are located in outward-looking communities, the effect of social pressure does not vary with distance, so we expect the impact of distance to headquarters on the share of fixedterm contracts in hiring to be positive and similar, whatever the degree of firm visibility. In contrast, this impact could be negative for firms that are highly visible at headquarters and with headquarters located in self-centered areas if the social pressure effect is strong enough.

CEOs are also likely to be more sensitive to the social pressure exerted by the local community at headquarters when they not only work but also live in that community. We have information on the CEO's place of living for a limited subsample of our data. We test this prediction by re-estimating equation [2.3] where the dummy variable for high/low firm visibility is replaced by a dummy variable capturing whether or not the CEO lives in the community of the firm's headquarters. As for visibility, we do so on the full sample and separately on firms with headquarters located in self-centered and outward-looking communities. On the full sample, we expect the impact of distance on the share of fixed-term contracts to be more positive if the CEO does not live in the community of the headquarters. In this case, the effect of monitoring and asymmetric information is indeed likely to dominate that of social pressure. When estimating our model on the sample of firms with headquarters located in outward-looking communities, we expect the impact of distance to be positive whatever the CEO's place of living, since the only effect varying with distance is that of monitoring and asymmetric information. In contrast, when headquarters are located in self-centered communities, the impact of distance should be more negative when CEOs live in the community of the headquarters as compared to when they do not. 


\section{The Data}

The data that we use come from matching several data sources. The first one is the social security records - the DADS, Déclarations Annuelles de Données Sociales over the period 1997-2009. They cover the universe of establishments and firms in all industries except agriculture, part of the food-processing industry and rural financial institutions (e.g. Crédit Agricole). They have yearly information on the municipality (or arrondissement ${ }^{25}$ ) where the establishment is located as well as its age and industry. They also provide the number of employees as well as the gender and (1-digit) occupational structure of the workforce as of December $31^{\text {st }}$ of each year. Therefore, we lag these variables by one year to use them as controls in our regressions.

For each establishment in the DADS, we know the identifier of its headquarters and the municipality/arrondissement where they are located. To the extent that $8.2 \%$ of our establishments change headquarters over the period under study, the location of the headquarters will be time-varying in our data. The DADS also has information on the legal category of the firm to which the establishment belongs (business company, public administration, charity etc.).

The visibility of a firm in the employment area of its headquarters is assumed to be an increasing function of its share of local employment. As can be seen in Appendix Table A2, the distribution of the shares of firms' employment in the employment area of their headquarters is quite skewed. So, in our empirical analysis, we capture high visibility with a dummy variable equal to 1 when the firm belongs to the upper $25 \%$ of the distribution and 0 otherwise. Similarly, low visibility is captured by a dummy variable equal to 1 when the firm belongs to the lower $75 \%$ of the distribution and 0 otherwise.

The second source that we use is the DMMO/EMMO databases. The DMMO (Déclarations sur les Mouvements de Main-d'Oeuvre) has exhaustive quarterly data on gross worker flows for establishments with 50 employees or more. The EMMO (Enquête sur les Mouvements de Main-d'Oeuvre) has similar information on a representative sample of $25 \%$ of the establishments with 10 to 49 employees. ${ }^{26}$ Both databases have information on hiring flows (excluding temporary agency workers) and the type of contract on which employees are hired. ${ }^{27}$ We compute the shares of fixed-term contracts in hiring for each quarter over 1998-2009. Given

\footnotetext{
${ }^{25}$ Arrondissements are subdivisions of municipalities. They exist only for the three largest French cities: Paris, Lyon and Marseille.

${ }^{26} \mathrm{We}$ do not have any information on worker flows for establishments with less than 10 employees.

${ }^{27}$ The type of contract is not available for transfers. So, we cannot include them in our analysis.
} 
that firms' headquarters only vary on a yearly basis, we then aggregate the share of fixed-term contracts in hiring at the year level.

The Répertoire Géographique des Communes ${ }^{28}$ provides information on the latitude and longitude of municipalities. Similar information for the arrondissements of Paris, Lyon and Marseille has been gathered from the website Carte de France. ${ }^{29}$ Great-circle distances between establishments are computed assuming that each establishment is placed at the barycentre of the municipality/arrondissement to which it belongs. This is, of course, a simplifying assumption. However, given that the largest cities are divided into arrondissements and that there are 36,570 municipalities in France - of which only 0.04\% have a surface larger than 190 $\mathrm{km}^{2}$ - the error we are making on the actual location is very small. ${ }^{30}$ Given our definition of distance, the distance between two establishments located in the same municipality/arrondissement is zero by construction. We also have information on the 94 départements to which municipalities belong and the Base Communale des Zones d'Emploi allows us to know in which employment area each municipality is located. ${ }^{31}$

Our key measure of self-centeredness of the area where the firm's headquarters are located is based on the differential turnout rates at local versus national elections. The underlying assumption behind this measure is that more self-centered individuals will be relatively more concerned by local stakes than by national ones, so that their participation to local elections (as compared to national ones) will be higher. In the literature, election turnout is classically considered as a measure of civic engagement (Guiso, Sapienza and Zingales, 2004). To the extent that we want to capture self-centeredness rather than civic attitude, we use the difference between two turnout rates that are likely to be influenced in similar ways by individuals' civic engagement. Election turnout rates are provided by the French Ministry of Interiors for all French départements. We proxy self-centeredness with the difference between the département-level turnout rates (in \% of registered voters) at the first round of the 2001 municipal elections and at the 2000 national referendum (on the 5-year - instead of 7-year term for the President of the Republic). We use the 2000 referendum rather than the 2002 parliamentary elections since French Members of Parliament (MP) are elected through a firstpast-the-post system. Constituencies are rather small and candidates often represent local

\footnotetext{
${ }^{28}$ This database is produced by the French Institut National de l'Information Géographique et Forestière (IGN).

${ }^{29} \mathrm{http}: / / \mathrm{www}$.cartesfrance.fr/

30 All French municipalities but nine are no larger than a square of $14 \times 14 \mathrm{~km}$. Therefore, assuming that establishments are located at the barycentre implies that the maximum possible error for these 36,561 municipalities is less than $10 \mathrm{~km}$.

${ }^{31}$ This database is provided by the French Statistical Institute (INSEE).
} 
interests: many of them also have a local mandate - as mayor or member of the département council - which they can maintain once elected as MP. As a consequence, election turnout in parliamentary elections is partly motivated by local stakes, in addition to national ones.

We validate our measure of self-centeredness using the 2008-2010 wave of the European Value Study (EVS). This survey covers 47 countries including France and provides information on political engagement and moral values of individuals. It is commonly used in the literature in sociology to contrast individuals caring essentially about their close relations to individuals caring about humanity as a whole (Rimac and Zrinscak, 2010; VanHeuvelen and Robinson, 2017; Waytz et al, 2019). People are indeed asked: "Do you feel concerned about: (1) Immediate family, (2) People in the neighbourhood, (3) Human kind?". Answers range from 1 to 5 corresponding to "not at all", "not so much", "to a certain extent", "much", "very much". We measure self-centeredness by the difference between the average score obtained by the individual when answering questions (1) and (2) and the score obtained when answering question (3). We do not use this measure in our main analyses since we cannot compute the average self-centeredness in the département where the individual lives at the time of the survey. The survey indeed only reports the administrative region (which contains several départements) where the individual lives in 2008-2010 and the département in which he or she was living at age 14. Moreover, for most of these départements, the number of observations is very small. ${ }^{32}$ We use this information to check that differential election turnout properly captures self-centeredness. In Appendix Table A3 - Panel A, we regress individual selfcenteredness as measured in the EVS on the average differential election turnout in the individual's region of residence and cluster standard errors at the regional level. As evidenced in column (1), the raw correlation is positive and significant at the $1 \%$ level. When adding controls for gender, age (6 classes), education (3 classes), employment status (8 classes) and household income (12 classes), the point estimate slightly increases and remains significant at the $1 \%$ level - see col (2). Including additional controls for whether the individual would vote if general elections would take place the day after and for how often the individual discusses political matters with friends (never, sometimes, often) does not change the results - see col (3). This suggests that differential election turnout between local and national elections computed at the regional level is strongly correlated with individual self-centeredness as measured in the EVS. As a robustness check, Table A3 - Panel B estimates the correlation between the EVS measure of individual self-centeredness and the average differential election

\footnotetext{
${ }^{32}$ On the subsample of individuals who have not changed region of residence since age 14, 6 départements have no observations and only $49 \%$ have at least 10 observations.
} 
turnout in the département where the individual was living at age 14 - on the subsample of individuals who have not changed region of residence since age 14. The results are highly similar to those in Panel A. These findings provide evidence that differential election turnout is a good proxy of self-centeredness.

To build the measure of self-centeredness that we use in our regressions, we attribute headquarters to the département where they are located and rank them according to the level of differential election turnout in their département. We then partition headquarters according to their rank in two groups of equal size, i.e. using the median of the distribution of differential election turnout across headquarters as the cut-off point. We consider the département of the headquarters as "self-centered" when the difference in turnout rates between municipal and national elections is above the median and "outward-looking" otherwise. Descriptive statistics for differential turnout rates are provided in Appendix Table A4. The difference is positive all over the distribution, indicating that election turnout was systematically higher at the 2001 municipal elections than at the 2000 national referendum. The distribution of differential turnout rates across départements is provided in Appendix Figure A1.

We also build a secondary measure of self-centeredness based on charity donations. The underlying assumption is that outward-looking individuals will be more prone to make donations. The advantage of this measure is that we have access to historical data on charity giving. This allows us to make sure that our results are not driven by a correlation between local economic conditions, self-centeredness and the share of fixed-term contracts in hiring. However, a key drawback of this measure is that it may not properly capture self-centeredness to the extent that self-centered individuals may be generous if they are sure that their donations are used for local purposes. If this is the case, our measure of self-centeredness will be somewhat noisy. The data we use come from the 1890 Annuaire Statistique de la France, from which we compute the total département-level receipts of secular charity centres as of 1887. Data are missing for a few départements ${ }^{33}$ because their borders have changed since the $19^{\text {th }}$ century. We standardise these donations by département $\mathrm{GDP}^{34}$ - see Appendix Table A4. We classify départements into two groups, selfish and generous, using the same criteria as for

\footnotetext{
${ }^{33}$ Moselle, Meurthe-et-Moselle, Haut-Rhin, Bas-Rhin, Territoire de Belfort, Paris, Hauts-de-Seine, Seine SaintDenis, Val de Marne, Essonne, Val d'Oise and Yvelines.

${ }^{34}$ Note that the ratio of historical donations to GDP is correlated with the current (2003-2010) ratio of charity donations to taxable income (computed at the level of départements). The estimated correlation coefficient is 0.22 , statistically significant at the 5\% level of confidence. The source of current charity donations and taxable income is the French Ministry of Finance. Historical département-level GDP is provided by Delafortrie and Morice (1959). It is measured as of 1864 , which is the year closest to 1887 for which such information is available.
} 
election turnout, i.e. the median of the charity distribution across headquarters. This grouping represents an imperfect alternative to the self-centered/outward-looking grouping.

We match these data sources and keep all business companies - excluding non-profit organizations (charities, foundations, etc.) and public administrations. We only keep firms with at least two secondary establishments in our dataset ${ }^{35}$ since we compare the shares of fixedterm contracts across firms' secondary establishments. We drop establishments for which the proportion of fixed-term contracts in hiring or some of our establishment-level controls are missing. The distribution of headquarters by employment area is presented in Appendix Figure A2. As standard in the literature in economic geography (e.g. Combes et al, 2010), we exclude establishments with headquarters located in the Paris area and its close suburbs (the so-called "Petite Couronne"). France being a highly centralised country, these headquarters represent more than $30 \%$ of all headquarters in France. We want to avoid that these might drive our results, all the more that Paris and its close suburbs turn out to be systematically outwardlooking areas. ${ }^{36}$ Our final sample contains 23,126 distinct establishments belonging to 4,954 different firms.

Starting in 2003, the DADS dataset also allows us to determine where CEOs live to the extent that they are wage-and-salary employees of their firm. Unfortunately, in France, this is not always the case since CEOs may alternatively be mandataires sociaux who are assimilated to self-employed from the point of view of social security and are hence out of the scope of the DADS. So, we have information on the CEOs' place of living only for a fraction of the observations in our preferred sample, namely 2,019 firms covering 7,015 establishments. We use these data to construct a dummy variable equal to 1 if the CEO lives within $50 \mathrm{~km}$ from the firm's headquarters and 0 otherwise. Symmetrically, we define a dummy variable equal to 1 if the CEO lives further away from the headquarters and 0 otherwise. In this subsample $74.6 \%$ of CEOs live and work at the firm's headquarters.

Descriptive statistics of our main regression sample are provided in Appendix Table A5. The unweighted average share of fixed-term contracts amounts to about $57.5 \%$ of hiring in our data. To get a picture of aggregate hiring flows, we can compute the weighted sum of the number of hires on fixed-term contracts over all establishments for each quarter and divide it by the weighted sum of all hiring in all establishments. ${ }^{37}$ The resulting aggregate figure is $73.2 \%$

\footnotetext{
35 These establishments may not be observed the same year. For example, in the case of 2 establishments, one of them may be observed at one year and the other one at another year.

${ }^{36}$ Putting Paris and close suburbs back into the sample yields qualitatively similar results.

${ }^{37}$ Using aggregation weights provided in the DMMO-EMMO.
} 
which is very close to the one provided by the French Ministry of Labor for the period 19992009 for the whole of France, i.e. 71.8\% - see DARES (2015). The gap between the aggregate and the unweighted figures suggests that large establishments (with large hiring volumes) are characterised by shares of fixed-term contracts that are larger than average.

Given that our model estimates the impact of distance to headquarters on the share of fixed-term contracts controlling for headquarters fixed effects, we want to make sure that the variation in the share of fixed-term contracts across establishments of a given firm is large enough. To do so, we decompose the variance of this share between a within and a betweenestablishment component. The between component accounts for $77 \%$ of the variance, which is far from negligible.

The mean and median numbers of secondary establishments per firm and year in our sample are 3 and 1 respectively - see Appendix Table A6 - col (1). Over the period 1998-2009, the average number of headquarters per firm in our sample is 1.17 . The average distance between secondary establishments and headquarters is $239 \mathrm{~km}$ - see Appendix Table A7. The mean distance to the closest establishment is $97 \mathrm{~km}$, and $263 \mathrm{~km}$ to the farthest establishment.

\section{Results}

\subsection{Main Results}

Table 1 presents the IV estimates of the impact of distance to headquarters on the share of fixed-term contracts in hiring. ${ }^{38}$ Our specification includes year dummies, headquarters fixed effects as well as a number of establishments' characteristics: establishment age (6 classes) and size ( 7 classes), the occupational and gender structure of the workforce, the firm size in the establishment's employment area (6 classes), 2-digit industry dummies, time-varying unemployment in the département where the establishment is located, employment-area fixed effects and 4 dummies for missing establishment in a given quarter. Controlling for establishment sector and age is important since this is a way to capture the level of risk that establishments are facing. Haltiwanger, Jarmin and Miranda (2013) indeed show that younger

\footnotetext{
${ }^{38}$ OLS estimates of equation [2.1] are presented in Table A8 in the Appendix. For establishments of firms with headquarters in outward-looking/generous départements, the impact of distance to headquarters on the share of fixed-term contracts in hiring is virtually zero - see Table A8 cols (2) and (4). This is due to the fact that, when estimated by OLS, this relation suffers from selection bias since establishments located far away from headquarters undergo the most serious monitoring problems so that they may not survive or may not even be created. This generates a downward bias in the estimates. In contrast, for establishments of firms with headquarters located in self-centered/selfish départements, the point estimate on distance is negative and significant - see Table A8 cols (3) and (5).
} 
establishments are more volatile. If they are also located closer to headquarters - as evidenced by Neumark, Zhang and Ciccarella (2008) in the case of Wal-Mart supermarkets -, this could bias our results. Large plants may also be located closer to headquarters and we have remarked above that they tend to have a greater share of fixed-term contracts amongst new hires. By contrast, firms with several establishments in the same employment area, and therefore a large overall size in that area, may employ a larger share of individuals on permanent contracts to the extent that it may be easier for them to relocate employees to another plant in case of negative shock. This is why we control for both establishment size and firm size in the establishment's employment area. The occupational and gender structure of the workforce may also matter since women and unskilled employees may be more likely to be on fixed-term contracts. Finally, we control for time varying unemployment because, beyond time-invariant characteristics of local labor markets, establishments located in more dynamic areas may be more likely to have larger shares of fixed-term contracts.

As indicated by the first-stage coefficients, whatever our specification, potential distance to headquarters is strongly correlated with actual distance so that our instrument is not weak - see Table 1.

Column 1 of Table 1 presents the second-stage estimates on our full sample of observations. The impact of distance to headquarters on the share of fixed-term contracts is small and insignificant at conventional levels. This is not inconsistent with our theory. To the extent that our sample is composed of firms with headquarters located in both self-centered and outward-looking communities, the average impact of distance to headquarters on fixed-term contracts results from two counteracting effects - i.e. monitoring/asymmetric information and local social pressure - which makes it ambiguous. When considering separately establishments of firms with headquarters located in self-centered/selfish and outward-looking/generous départements, the pattern of impact of distance to headquarters on the share of fixed-term contracts in hiring is opposite across firm types. For establishments with headquarters located in outward-looking départements as measured on the basis of differential turnout at the local and national elections, distance to headquarters has a positive and significant impact on the share of fixed-term contracts in hiring - see Table 1, col (2). In the absence of social pressure aiming at protecting jobs located close to headquarters, the only effect that is at play is that of asymmetric information and monitoring: since establishments located further away from headquarters are harder to manage, they face more frequent shocks and hence rely more on fixed-term contracts when hiring. In contrast, for establishments with headquarters located in 
self-centered départements, local social pressure plays an important role, beyond monitoring problems. As a matter of fact, the impact of distance to headquarters on the share of fixed-term contracts turns out to be negative and the point estimate in Table 1, col (3) is significantly different from the corresponding one in col (2) at the $0.1 \%$ level. ${ }^{39}$ This suggests that the pressure exerted by the local communities at headquarters in order to avoid dismissals at short distances overcomes the effect of monitoring and asymmetric information. ${ }^{40}$ As a consequence, establishments located closer to headquarters hire more on fixed-term contracts. From a quantitative point of view, our results imply that when distance to headquarters increases by one standard deviation $(218.9 \mathrm{~km})$, the share of fixed-term contracts decreases by 6 percentage points $(218.9 \times 0.0273)$ - see col $(3)$ - i.e. by $10.3 \%$ as measured at the sample average $(57.5 \%)$, which is far from negligible. ${ }^{41}$

Results are similar when self-centered/outward-looking attitude is proxied by selfishness/generosity as measured on the basis of historical charity donations - see Table 1, cols (4) and (5). To the extent that generosity has been shown to be correlated with income Card, Hallock and Moretti (2010) - one could be concerned that these results capture differences in income per capita rather than self-centeredness across départements. This turns out not to be the case. If splitting our sample between high and low-income départements rather than between generous and selfish départements - we indeed find no significant effect of distance on the share of fixed-term contracts in hiring neither when headquarters are located in high-income nor in low-income départements. ${ }^{42}$

As discussed in Section 1, CEOs are likely to be subject to social pressure only if their firm is visible in the local community of their headquarters. To test for this prediction, we estimate equation [2.3] considering that a firm is highly visible when it accounts for a large

\footnotetext{
${ }^{39}$ As shown in Appendix Table A9, these findings are robust to using, as an instrument, a measure of potential distance constructed using an arbitrary constant instead of ruggedness - see footnote 24 .

${ }^{40}$ As a robustness check, we augment our specification including occupation-by-employment area dummies and occupation-by-département-by-year dummies. To do so, we reshaped our dataset. We define our observations at the occupation-by-establishment-by-year level where the occupational categories we consider are managers, board members and professionals, technicians, clerks, skilled blue-collars and unskilled blue-collars. Our dependent variable is in this case the share of fixed-term contracts in hiring within each occupation of each establishment at each year. Re-estimating our model with either of these two additional sets of controls leaves our results unchanged. Detailed results are available upon request.

${ }^{41}$ These specifications include 51 industry dummies and 6 establishment age classes to control for the level of risk that establishments are facing. Our results are unchanged if we use either industry-by-time dummies or more detailed controls by including 719 industry dummies and 101 age classes (results available upon request).

${ }^{42}$ The point estimate (resp. standard error) for distance is $0.0079(0.0131)$ when estimated on the sub-sample of establishments with headquarters located in high-income départements and $0.0081(0.0067)$ when estimated on establishments with headquarters located in low-income départements. Similarly to what has been done for selfcenteredness and selfishness, the cut-off used to distinguish between the two groups is the cross-headquarters median of GDP per capita as computed from département-level data dated 1864.
} 
share of employment in the employment area of its headquarters. Since firm visibility is likely to be strongly correlated with local firm size, we control for the interactions between distance to headquarters and a set of dummies of firm size in the employment area of the headquarters. In addition, since visibility may also be correlated with the overall size of the firm in France, we also include a control for distance to headquarters interacted with a dummy variable for large firms where large is defined as the top $25 \%$ of the distribution in the whole of France results are however similar if these controls are not included. As shown in Table 2 col (1), when estimated on the full sample of establishments, the impact of distance on the share of fixedterm contracts in hiring is positive, although insignificant, for establishments of firms with low visibility. This is consistent with our theoretical framework, since for firms that are hardly visible at headquarters, social pressure is likely to be inexistent so that the effect of monitoring and asymmetric information problems dominates. This generates a positive relationship between distance to headquarters and the share of fixed-term contracts. In contrast, for firms that are highly visible at headquarters, the effect of social pressure is much stronger and offsets that of monitoring and asymmetric information. As a consequence, the impact of distance to headquarters on the share of fixed-term contracts turns out to be negative although not significant at conventional levels, and the difference in point estimates between distance interacted with respectively high and low visibility is significant at the $5.2 \%$ level.

Results obtained when estimating our model separately on establishments of firms with headquarters located in self-centered and outward-looking départements are consistent with this pattern of results. When firms' headquarters are located in outward-looking départements, social pressure arising from the local community does not vary with distance so that the effect of monitoring and asymmetric information dominates - see cols (2) and (4) of Table 2: whatever the visibility of the firm at headquarters, the point estimates of distance to headquarters are positive and not significantly different from each other. In contrast, for firms with headquarters located in self-centered départements, social pressure plays an important role when the firm is highly visible at headquarters - see cols (3) and (5): in this case, the impact of distance on the share of fixed-term contracts is negative and significant at the 5\% level. This confirms that establishments located close to headquarters tend to hire more on fixed-term contracts as a way to escape social pressure when their firm is highly visible at headquarters and the latter are located in a self-centered community. Conversely, whenever local communities at headquarters are self-centered but the firm is not visible, the impact of distance on the share of fixed-term contracts in hiring is positive although insignificant. 
We also expect CEOs to be more sensitive to social pressure when they not only work but also live in the community of the firm's headquarters. To test for this prediction, we reestimate equation [2.3], substituting dummy variables for CEOs living/not living at headquarters for firms' high/low visibility. When estimating our model on the full sample of establishments, the impact of distance on the share of fixed-term contracts in hiring is positive (significant at the 1\% level) when CEOs do not live at headquarters - see Table 3, col (1). In this case, their sensitivity to social pressure is low so that the effect of monitoring and asymmetric information dominates, which generates a positive relationship between distance to headquarters and the share of fixed-term contracts. In contrast, when CEOs live at headquarters they are more sensitive to social pressure, which counterbalances the effect of monitoring and asymmetric information. In this case, the impact of distance to headquarters on the share of fixed-term contracts turns out to be insignificant at conventional levels.

We then estimate our model separately on establishments of firms with headquarters located in outward-looking and self-centered départements. As expected, for firms with headquarters located in outward-looking départements, the impact of distance to headquarters on the share of fixed-term contracts is positive whatever the place of living of the CEO - see Table 3, cols (2) and (4) - and the difference in point estimates between distance interacted with CEO living and not living at headquarters is not significant. This result holds whether we measure self-centeredness based on election turnout or charity giving. Conversely, for firms with headquarters in self-centered départements, distance to headquarters has a negative and significant effect on the share of fixed-term contracts when CEOs live at headquarters, while the effect is positive for CEOs not living at headquarters - see Table 3, cols (3) and (5) -, and the difference in point estimates between CEOs living and not living at headquarters is significant at least at the $6 \%$ level. These findings yield support to the hypothesis that CEOs are more sensitive to social pressure in the community of the headquarters when they live in that community.

\subsection{Robustness Checks and Extensions}

To the extent that the evidence we provide relies on separate estimates conducted on establishments of firms with headquarters located in self-centered vs outward-looking communities, one could be concerned that having headquarters located in one type of community or the other could be correlated with firm characteristics that could influence the relationship between distance and the share of fixed-term contracts. To tackle this issue, we 
estimate, on our full sample of observations, a model in which the share of fixed-term contracts is regressed on distance to headquarters interacted with the dummy variables for selfcenteredness and outward-looking attitude, controlling for a rich set of additional interactions between distance and a series of firm characteristics. These characteristics include the most important 1-digit industry within the firm, firm age, the occupational structure of the workforce, total firm size in France and the log average daily labor cost per worker as a proxy of firm productivity. In an alternative specification, we replace industry dummies with the standard deviation of firm employment growth within each 2-digit sector, in order to better capture the intrinsic level of risk in each industry. The results are provided in Appendix Table A11. To start with, columns (1) and (4) estimate a model which only includes the same baseline establishment-level controls as those used in Table 1. As expectable, the results of this specification are similar to those in Table 1 - columns (2) and (3) for election turnout and (4) and (5) for charity giving $-:{ }^{43}$ whatever measure of self-centeredness we use, distance has a positive and significant impact on the share of fixed-term contracts in establishments with headquarters located in outward-looking départements, while its impact is negative and significant for establishments with headquarters located in self-centered communities. The difference in the point estimates of distance interacted respectively with outward-looking and self-centered communities at headquarters is also highly significant. When adding controls for distance interacted with firm characteristics, the results are essentially unchanged: both in the election turnout and the charity giving panels, distance has a negative impact on the share of fixed-term contracts when firms' headquarters are located in self-centered communities, while its effect is positive when firms' headquarters are located in outward-looking communities, with the difference in point estimates being highly significant - see columns (2), (3), (5) and (6). These findings suggest that that the negative effect of distance on the share of fixed-term contracts that we find when headquarters are located in self-centered départements is unlikely to be due to specific firms locating their headquarters in this type of community.

Another worry could be that our measure of self-centeredness based on election turnout dates back to year 2001 and therefore is not pre-dated with respect to our sample, which spans from 1998 to 2009. This could be a problem if the difference in turnout rates between municipal and national elections is simultaneously correlated with local economic conditions and the share of fixed-term contracts in hiring. To overcome this problem, we re-estimate columns (2) and

\footnotetext{
${ }^{43}$ In fact, the coefficients reported in Table 1 can be seen as the results of the estimation of a model in which each covariate has been interacted with dummies for self-centered and outward-looking départements. As such, the model underlying column (1) in Table A11 can be seen as a constrained version of the model underlying columns (2)-(3) of Table 1.
} 
(3) of Table 1 on a reduced sample limited to years 2003-2009. The results are unchanged: the point estimate (resp. standard error) on distance is 0.0204 (0.0056) when headquarters are located in outward-looking communities and -0.0235 (0.0081) when headquarters are located in self-centered communities.

Given that our main measure of self-centeredness is based on the difference between turnout rates at local and national elections, a worry could be that whether a département turns out to be self-centered or outward-looking is entirely determined by its turnout rate at one of the two elections. In this case, our results could be due to differences in civic engagement across départements rather than to self-centeredness. To tackle this issue, we re-estimate equation [2.1] separately on départements with election turnout above and below the median at local elections - rather than with differential election turnout above or below the median. We find no significant effect of distance on the share of fixed-term contracts in hiring in either of the two subsamples. ${ }^{44}$ The same goes when splitting our sample between départements with election turnout above and below the median at the national referendum. ${ }^{45}$ This suggests that our main results are not due to local differences in civic engagement.

Since hiring costs are likely to vary with the skill level of the workers, we are interested in investigating whether the impact of local social pressure on the type of employment contract varies across high and low-skilled workers. To do so, we reshape our dataset and re-define our observations at the occupation-by-establishment-by-year level (see also footnote 40). Our dependent variable is in this case the share of fixed-term contracts in hiring within each occupation of each establishment in each year. We re-estimate the specification in Table 1 on these new data adding an interaction term between distance and a dummy variable indicating whether the occupation we consider is high or low skilled. The high-skill category includes managers, board members and professional. The low-skill category includes technicians, clerks and blue-collars. The point estimates on the Distance*High-skill and Distance*Low-skill variables are both negative and not significantly different one from the other. ${ }^{46}$

Our theory relies on the assumption that adjustment costs associated to dismissals decrease as social ties get looser. So, an additional test consists in re-estimating our main

\footnotetext{
${ }^{44}$ The point estimate (resp. standard error) for distance is 0.0097 (0.0078) when estimated on the sub-sample of establishments with headquarters located in départements where election turnout is above the median at local elections, and $0.0066(0.0074)$ when estimated on establishments with headquarters located in départements where election turnout is below the median at local elections.

${ }^{45}$ The point estimate (resp. standard error) for distance is $0.0316(0.0196)$ when estimated on the sub-sample of establishments with headquarters located in départements where election turnout is above the median at the national referendum, and $0.0087(0.0090)$ when estimated on establishments with headquarters located in départements where election turnout is below the median at the national referendum.

${ }^{46}$ Results are available upon request.
} 
specification on our main dataset using a measure of distance based on social ties rather than kilometers. We consider that an establishment is close to its headquarters when a high proportion of individuals living at headquarters were born in the geographical area of the establishment. When re-estimating our model with this measure of social distance, we find similar results to those obtained using physical distance - see Appendix A.3.

\section{Alternative Explanations}

Could factors other than local social pressure account for the negative relationship that we find between distance to headquarters and the share of fixed-term contracts in hiring when firms' headquarters are located in self-centered communities? This is what we investigate in this section.

One reason why firms could rely more on fixed-term contracts at short distance from headquarters is that there is no need to offer permanent contracts to attract high-productivity employees since the proximity with the firm's management is enough to make jobs attractive. This would generate a negative relationship between distance to headquarters and the share of fixed-term contracts in hiring. However, this relation should hold whatever the degree of selfcenteredness of the local community at headquarters while we observe that this is the case only for firms with headquarters located in self-centered communities. For firms with headquarters in outward-looking départements, this relation is indeed positive and significant at the $1 \%$ level.

The negative relationship we find between distance to headquarters and the share of fixed-term contracts in hiring could also originate from workers' screening. Firms may be more selective when hiring workers closer to headquarters because the jobs at stake involve more responsibility. If, as suggested by Faccini (2014), temporary contracts are used as screening devices allowing firms to learn about workers' productivity, these contracts may be more in use closer to the firms' headquarters. However, here again, this relationship should hold whatever the degree of self-centeredness of the local community at headquarters, which is not the case in our results. Moreover, there is no reason that this relationship varies with firm visibility or with the place of living of the CEO.

Local employment subsidies may be another factor driving our results. They are typically given to firms (that are profit centres) and not establishments (that are not). If local authorities condition these subsidies on the fact that they are used for hiring workers locally, firms will hire more workers close to headquarters and, if they perceive the subsidies as 
temporary, the new hires will be on fixed-term contracts. This could account for the negative relationship between distance to headquarters and the share of fixed-term contracts in hiring. However, we do not find any impact of distance to headquarters on total hiring - see Table A10 -, even in establishments of firms with headquarters located in self-centered départements. This suggests that local subsidies are unlikely to explain our results.

Our finding that highly-visible firms tend to hire more workers on fixed-term contracts at short distance from headquarters could be due to the fact that these firms are large and hence have an important monopsony power on their local labor market. This would allow them to offer poorer job-quality employment contracts close to their headquarters. However, if this mechanism were a key driver of our results, this relation should hold whatever the degree of self-centeredness of the local community at headquarters. In contrast, we find this effect only when headquarters are located in self-centered départements: when headquarters are located in outward-looking communities, we find that firms hire fewer workers on fixed-term contracts at short distance from headquarters and this effect does not vary whether firms are highly visible or not.

Firms with headquarters in rural areas could locate some specific functions (e.g. R\&D) further away from headquarters as compared to what they would do if their headquarters were located in urban areas. If the corresponding employees tend to be employed on open-ended contracts and if self-centeredness correlates with rurality, this could generate a negative relationship between distance and the share of fixed-term contracts in hiring. In order to tackle this issue, we estimate, on our full sample of observations, a model in which the share of fixedterm contracts is regressed on distance to headquarters interacted with self-centeredness and outward-looking attitude on the one hand, and with a dummy variable for rural/urban département at headquarters as of year 2000, on the other hand. The corresponding results are presented in Appendix Table A12. Column (1) is identical to the first column of Table A11: it reports the results obtained when estimating a model which only includes the same baseline controls as in Table 1. The results are very similar when adding a control for distance interacted with a dummy variable for rural/urban département at headquarters - see col (2).

However, one could argue that rurality is a more continuous characteristic than what we capture with our dichotomous variable. To account for this possibility, we re-estimate the same model as in col (2) controlling for distance to headquarters interacted with other measures of economic development that could induce firms to locate R\&D - or other highly-skilled functions - further away from their headquarters, i.e. GDP per capita in 2005 , the employment 
share of the tertiary sector (excluding public administration) in 2000, the time-varying unemployment rate and the share of individuals aged 16 or more who are not in education and have a diploma higher than upper secondary education - see Table A12, col (3). ${ }^{47}$ The results are very similar to those obtained in col (2): the impact of distance on the share of fixed-term contracts is negative and significant when headquarters are located in self-centered communities, while it is positive although insignificant when headquarters are located in outward-looking communities. This suggests that the negative effect of distance on the share of fixed-term contracts that we find when headquarters are located in self-centered départements cannot be explained by rurality.

One could also worry that our results are not driven by local social pressure but rather by the fact that CEOs share the same values as their local community's. They would thus tend to be self-centered when the local community is so, and hence try to avoid dismissing workers at short distances from headquarters because they care for their local community. However, CEOs who care for their local community would not choose to hire workers on fixed-term rather than permanent contracts since the former entail greater job insecurity and hence lower job quality. This is all the more likely that, in contrast to the local community, CEOs do observe the type of employment contract they offer.

A last concern could be that our regressions could capture the effect of some geographic characteristics of the establishments located in the same département as their headquarters. By construction these establishments are at low distance from these headquarters. Moreover, their geographic characteristics could be correlated both with self-centeredness and with the propensity to use fixed-term contracts in that département. However, all our specifications include very detailed employment-area fixed effects, thereby netting out our estimates from any geographical effect of this type.

\section{Conclusion}

This paper has examined the impact of local social pressure on the choice of employment contracts. We have shown that for firms with headquarters located in self-centered

\footnotetext{
${ }^{47}$ Self-centeredness, rural/urban dummies and extended controls interacted with potential distance are used as instruments. The Angrist-Pischke F-test on Distance*Outward-looking is rather low (8.26 and 4.81, respectively) in columns (2) and (3). Given that our model has as many instruments as endogenous variables, it is just identified. As underlined by Angrist and Pischke (2009), just-identified 2SLS estimators are median-unbiased and confidence intervals are reliable except when the Angrist-Pischke F-test statistics are very close to 0 , which is not the case here.
} 
communities, the share of fixed-term contracts in hiring is larger in establishments located closer to headquarters while the opposite holds for firms with headquarters located in outwardlooking communities. These findings hold whether we use a measure of self-centeredness based on differential election turnout or we proxy it with selfishness based on charity giving. They are also robust to using a measure of distance to headquarters based on social ties rather than geography. We have also shown that the negative impact of distance to headquarters on the share of fixed-term contracts when headquarters are located in self-centered communities is concentrated on firms that are highly visible at headquarters and whose CEOs not only work but also live in the community of the headquarters. This suggests that when CEOs are subject to local social pressure against dismissals, they try to escape it by hiring workers on fixed-term contracts. We have shown that these findings are consistent with an adjustment-cost model of employment-contract decisions made by CEOs under the threat of local social sanctions. In contrast, they cannot be accounted for by alternative mechanisms involving workers sorting or screening, CEOs' altruism, local employment subsidies, monopsony power or geographical confounders.

Beyond fixed-term contracts, one could expect that other forms of employment that do not entail any commitment to long-term relationships, such as the use of independent contractors or temporary help workers, would represent alternative ways for CEOs to escape local social pressure. One could conjecture that establishments of firms with headquarters located in self-centered communities would make greater use of those contracts when located close to the firms' headquarters. Our data do not allow us testing this hypothesis but this would be a highly valuable contribution to our understanding of the development of non-standard forms of work.

In addition to local social pressure, firms' employment decisions are also likely to react to the threat of social sanctions on a larger scale, typically national or international. For example, the campaign against the use of child labor by Nike in 1996 indeed turned out to have substantially changed the human resource practices of the company since then. ${ }^{48}$ Moreover, the growing development of social networks should, if anything, strengthen the impact of the national and/or international reputation of firms on their sales and ultimately on their profits. In this context, the effects of social pressure on firm behavior, including hiring and firing policies, could be even more important than what identified in this paper by focusing only on the local

\footnotetext{
${ }^{48}$ See for example John H. Cushman Jr., "Nike Pledges to End Child Labor and Apply U.S. Rules Abroad", The New York Times, May 13, 1998.
} 
dimension of social pressure. Investigating this issue would be a fascinating avenue for future research.

\section{References}

Abraham, Filip, Tim Goesaert and Josef Konings. 2014. Staying Home or Moving Away? Restructuring Efforts within Multinational Enterprises. The World Economy, 37(6): 765-782.

Akerlof, George. 1980. A theory of social custom, of which unemployment may be one consequence. The Quarterly Journal of Economics, 94(4): 749-775.

Andreoni, James, and Ragan Petrie. 2004. Public goods experiments without confidentiality: a glimpse into fund-raising. Journal of Public Economics, 88(7-8): 1605-1623.

Angrist, Joshua, and Jörn-Steffen Pischke. 2009. Mostly Harmless Econometrics. Princeton: Princeton University Press.

Ariely, Dan, Anat Bracha, and Stephan Meier. 2009. Doing good or doing well? Image motivation and monetary incentives in behaving prosocially. American Economic Review, 99(1): 544-555.

Autor, David H. 2003. Outsourcing at Will: the Contribution of Unjust Dismissal Doctrine to the Growth of Employment Outsourcing. Journal of Labor Economics, 21(1): 1-42.

Bandiera, Oriana, Luigi Guiso, Andrea Prat, and Raffaella Sadun. 2015. Matching Firms, Managers, and Incentives, Journal of Labor Economics, 33(3): 623-681.

Baron, David. 2011. Credence attributes, voluntary organizations, and social pressure, Journal of Public Economics, 95, 1331-1338.

Bassanini, Andrea, Giorgio Brunello and Eve Caroli. 2017. Not in my community: Social Pressure and the Geography of Dismissals, Journal of Labor Economics, 35(2): 429-483.

Bassanini, Andrea, Eve Caroli, Bruno Chaves Ferreira, and Antoine Reberioux. 2020. Don't Downsize This! Social Reactions to Mass Dismissals on Twitter, IZA DP No. 13840.

Battiston, Pietro, and Simona Gamba. 2016. The impact of social pressure on tax compliance: A field experiment, International Review of Law and Economics, 46, 78-85.

Benabou, Roland, and Jean Tirole. 2006. Incentives and Prosocial Behavior. American Economic Review, 96(5): 1652-1678.

Bentolila, Samuel, Pierre Cahuc, Juan Dolado and Thomas Le Barbanchon. 2012. Two-Tier Labour Markets in the Great Recession: France Versus Spain. The Economic Journal, 122(562): F155-F187.

Berton, Fabio, and Pietro Garibaldi. 2012. Workers and Firms Sorting into Temporary Jobs. The Economic Journal, 122(562): F125-F154.

Bertrand, Marianne, and Sendhil Mullainathan. 2003. Enjoying the quiet life? Corporate governance and managerial preferences. The Journal of Political Economy, 111(5): 1043-1075.

Blanchard, Olivier, and Augustin Landier. 2002. The Perverse Effects of Partial Labour Market Reform: Fixed-Term Contracts in France. The Economic Journal, 112(480): F214-F244.

Boeri, Tito, and Jan van Ours. 2013. The Economics of Imperfect Labor Markets, Princeton University Press. 
Bottazzi, Laura, and Giovanni Peri. 2003. Innovation and spillovers in regions: evidence from European patent data. European Economic Review, 47(4): 687-710.

Briant, Anthony, Pierre-Philippe Combes, and Miren Lafourcade. 2010. Dots to boxes: do the size and shape of geographical units jeopardize economic geography estimations? Journal of Urban Economics, 67(3): 287-302.

Cahuc, Pierre, Oliver Charlot and Franck Malherbet. 2016. Explaining the Spread of Temporary Jobs and Its Impact on Labor Turnover, International Economic Review, 57(2): 533-572.

Cahuc, Pierre, and Fabien Postel-Vinay. 2002. Temporary Jobs, Employment Protection and Labour Market Performance. Labour Economics, 9(1): 63-91.

Card, David, Kevin F. Hallock, and Enrico Moretti. 2010. The geography of giving: the effect of corporate headquarters on local charities. Journal of Public Economics 94, no.3-4: 222-234.

Centeno, Mario, and Alvaro Novo. 2012. Excess Worker Turnover and Fixed-Term Contracts: Causal Evidence in a Two-Tier System. Labour Economics, 19(3): 320-328.

Charness, Gary, and David Levine. 2000. Are Layoffs Acceptable? Evidence from a QuasiExperient. Industrial and Labor Relations Review, 53(3): 381-400.

Charnoz, Pauline, Claire Lelarge and Corentin Trevien. 2018. Communication Costs and the Internal Organization of Multi-Plant Businesses: Evidence from the Impact of the French HighSpeed Rail, The Economic Journal, 128(610): 949-994.

Combes, Pierre-Philippe, Gilles Duranton, Laurent Gobillon, and Sébastien Roux. 2010. Estimating agglomeration economies with history, geology, and worker effects. In Agglomeration Economics, ed. Edward L. Glaeser (ed.). Cambridge, MA: The National Bureau of Economic Research.

Combes, Pierre-Philippe, Thierry Mayer, and Jean-François Thisse. 2008. Economic Geography. Princeton: Princeton University Press.

Cronqvist, Henrik, Fredrik Heyman, Mattias Nilsson, Helena Svaleryd, and Jonas Vlachos. 2009. Do entrenched managers pay their workers more? The Journal of Finance, 64(1): 30939.

DARES. 2015. Les mouvements de main-d'œuvre : Données annuelles, http://dares.travailemploi.gouv.fr/dares-etudes-et-statistiques/statistiques-de-a-a-z/article/les-mouvements-demain-d-oeuvre.

Delafortrie, Nicole, and Janine Morice. 1959. Les revenus départementaux en 1864 et 1954 , Paris, Armand Colin, 340p.

Della Vigna, Stefano, John List, and Ulrike Malmendier. 2012. Testing for altruism and social pressure in charitable giving. Quarterly Journal of Economics, 127(1): 1-55.

Devicienti, Francesco, Paolo Naticchioni and Andrea Ricci. 2018. Temporary Employment, Demand Volatility and Unions: Firm-Level Evidence, Industrial and Labor Relations Review, 71(1): 174-207.

Dräger, Vanessa, and Paul Marx. 2017. Do Firms Demand Temporary Workers When They Face Workload Fluctuations? Cross-Country Firm-Level Evidence, Industrial and Labor Relations Review, 70(4): 942-975.

EVS. 2010. European Values Study 2008: France. GESIS Data Archive, Cologne. ZA4751 Data file version 2.0.0. doi:10.4232/1.10198 
Faccini, Renato. 2014. Reassessing Labour Market Reforms: Temporary Contracts as a Screening Device. The Economic Journal, 124(575), 167-200.

Friebel, Guido, and Matthias Heinz. 2014. Media Slant Against Foreign Owners: Downsizing, Journal of Public Economics, 120, 97-106.

Funk, Patricia. 2010. Social Incentives and Voter Turnout: Evidence from the Swiss Mail Ballot System, Journal of the European Economic Association, 8(5): 1077-1103.

Gerber, Alan S., Donald P. Green and Christopher W. Larimer. 2008. Social Pressure and Voter Turnout: Evidence from a Large-Scale Field Experiment. American Political Science Review, 102(1): 33-48.

Giroud, Xavier. 2013. Proximity and investment: evidence from plant-level data. Quarterly Journal of Economics, 128(2): 861-915.

Giroud, Xavier, and Holger Mueller. 2010. Does corporate governance matter in competitive industries? Journal of Financial Economics, 95(3): 312-331.

Guiso, Luigi, Paola Sapienza and Luigi Zingales. 2004. The Role of Social Capital in Financial Development. American Economic Review, 94(3): 526-556.

Haltiwanger, John, Ron Jarmin, and Javier Miranda. 2013. Who creates jobs? Small versus large versus young. Review of Economics and Statistics, 95(2):347-61.

Harris, Chauncy D. 1954. The market as a factor in the localization of industry in the United States. Annals of the Association of American Geographers, 44(4): 315-348.

Heinz, Matthias, and Johan Swinnen. 2015. Media slant in economic news: A factor 20, Economics Letters, 132: 18-20.

Hendel, Igal, Saul Lach and Yossi Spiegel. 2017. Consumers Activism: the Cottage Cheese Boycott. RAND Journal of Economics, 48(4): 972-1003.

Hijzen, Alexander, Leopoldo Mondauto and Stefano Scarpetta. 2017. The Impact of Employment Protection on Temporary Employment: Evidence from a Regression Discontinuity Design. Labour Economics, 46(1): 64-76.

Hoffman, Mitchell, Lisa, Kahn, and Danielle Li. 2018. Discretion in Hiring. The Quarterly Journal of Economics, 133(2), 765-800.

Ioannides, Yannis, and Henry G. Overman. 2004. Spatial evolution of the US urban system. Journal of Economic Geography, 4(2): 1468-2710.

Kahn, Lawrence M. 2010. Employment Protection Reforms, Employment and the Incidence of Temporary Jobs in Europe: 1996-2001. Labour Economics, 17(1):1-15.

Kalnins, Arturs, and Francine Lafontaine. 2013. Too far away? The effect of distance to headquarters on business establishment performance. American Economic Journal: Microeconomics, 5(3): 157-79.

Landier, Augustin, Vinay Nair, and Julie Wulf. 2009. Trade-offs in staying close: corporate decision making and geographic dispersion. Review of Financial Studies, 22(3): 1119-1148.

Neumark, David, Junfu Zhang, and Stephen Ciccarella. 2008. The effects of Wal-Mart on local labor markets. Journal of Urban Economics, 63(2): 405-430.

Nunn, Nathan, and Diego Puga. 2012. Ruggedness: the blessing of bad geography in Africa, Review of Economics and Statistics, 94(1): 20-36.

OECD. 2013. Employment Outlook, Chapter 2, OECD: Paris. 
OECD. 2014. Employment Outlook, OECD: Paris.

OECD. 2016. Employment Outlook, OECD: Paris.

Rimac, Ivan, and Sinisa Zrinscak. 2010. Social Legacy and Social Values: a Post-Communist Experience, in Halman Loek and Malina Voicu eds, Mapping Value Orientations in Central and Eastern Europe, Boston, Brill, 107-137.

Rousseau, Denise, and Ronald Anton. 1988. Fairness and Implicit Contract Obligations in Job Terminations: A Policy-Capturing Study, Human Performance, 1(4): 273-289.

VanHeuvelen Tom and Robert Robinson. 2017. "And Who Is My Brother?" The Scope of Religious Communitarianism in Europe, Social Currents, 4(5), 482-506.

Waytz, Adam, Ravi Iyer, Liane Young, Jonathan Haidt and Jesse Graham. 2019. Ideological differences in the expanse of the moral circle, 10(4389), https://doi.org/10.1038/s41467-019$12227-0$. 


\section{Tables and Figures}

\section{Figure 1 - Job risk and contract choice}

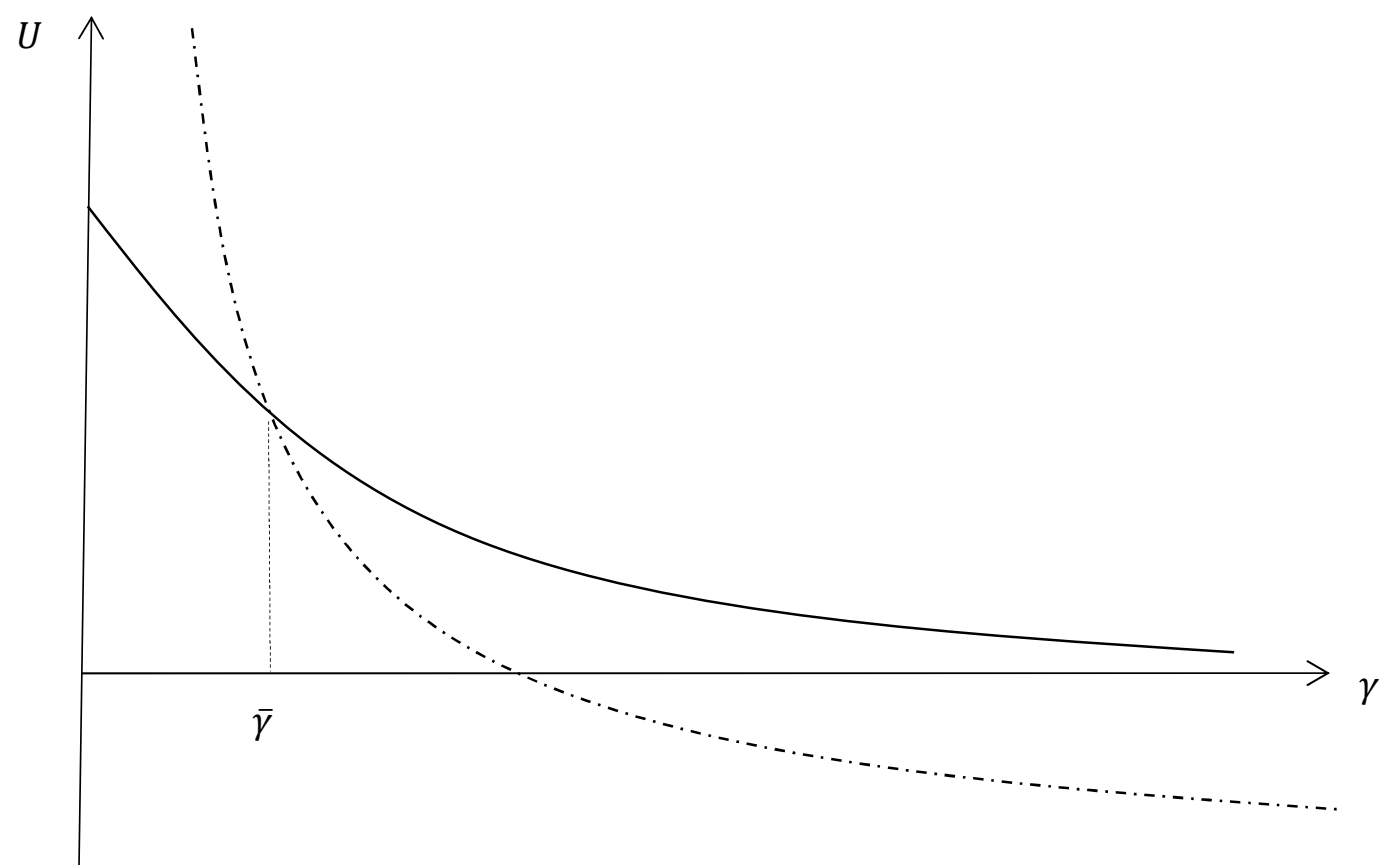

Note - the chart shows the utility derived from hiring on fixed-term or permanent contracts for different job risk levels. The continuous and dot-and-dashed lines represent the utility schedule for fixed-term and permanent contracts, respectively. 
Table 1 - Impact of distance to headquarters on the share of fixed-term contracts - IV estimates

\begin{tabular}{|c|c|c|c|c|c|}
\hline $\begin{array}{l}\text { Dep.var: } \\
\text { Share of fixed-term contracts }\end{array}$ & (1) & (2) & (3) & (4) & (5) \\
\hline \multicolumn{2}{|c|}{ Definition of self-centered/outward-looking } & \multicolumn{2}{|c|}{ Election turnout } & \multicolumn{2}{|c|}{ Charity giving } \\
\hline Département of Headquarters (HQ) & Full Sample & $\begin{array}{l}\text { Outward- } \\
\text { looking }\end{array}$ & Self-centered & Generous & Selfish \\
\hline Actual distance to HQ & $\begin{array}{c}0.0074 \\
(0.0062)\end{array}$ & $\begin{array}{c}0.0191 * * * \\
(0.0049)\end{array}$ & $\begin{array}{l}-0.0273 * * * \\
(0.0081)\end{array}$ & $\begin{array}{c}0.0154^{* * *} \\
(0.0029)\end{array}$ & $\begin{array}{c}-0.0247 * * * \\
(0.0075)\end{array}$ \\
\hline Control variables & yes & yes & yes & yes & yes \\
\hline Observations & 73,601 & 45,885 & 27,716 & 32,429 & 25,333 \\
\hline R-squared & 0.520 & 0.518 & 0.531 & 0.539 & 0.528 \\
\hline First stage coefficient on instrument & $\begin{array}{c}0.548 * * * \\
(0.092)\end{array}$ & $\begin{array}{l}0.475^{* *} \\
(0.186)\end{array}$ & $\begin{array}{c}0.462 * * * \\
(0.086)\end{array}$ & $\begin{array}{l}0.633 * * * \\
(0.138)\end{array}$ & $\begin{array}{c}0.545^{* * * *} \\
(0.038)\end{array}$ \\
\hline
\end{tabular}

Note - Models are estimated with 2SLS estimators. The dependent variable is the annual average share of fixed-term contracts in total hiring in percentage, as measured at the establishment level. Potential distance is used as an instrument. Actual and potential distances to headquarters are measured in kilometers. Control variables include establishment age (6 classes) and size ( 7 classes), occupational and gender structure of the establishment workforce, firm size in the establishment's employment area (6 classes), 2-digit industry dummies, time-varying unemployment at the département level, year dummies, 4 dummies for missing establishment in a given quarter and headquarters and employment-area fixed effects. Election turnout is measured as the difference between the département-level turnout rates (in $\%$ of registered voters) at the first round of the 2001 municipal elections and the 2000 referendum (on the 5-year - instead of 7-year - term for the President of the Republic). A firm is assumed to have headquarters located in an outward-looking département if its headquarters belong to the bottom half of the distribution of differential turnout rates. Symmetrically, firm headquarters are considered to be located in a self-centered département if they belong to the top half of the distribution. Charity giving is measured as the ratio of total charity donations in 1887 to département-level GDP. A firm is assumed to have headquarters located in a generous département if its headquarters belong to the top half of the charity giving distribution. Symmetrically, firm headquarters are considered to be located in a selfish département if its headquarters belong to the bottom half of the distribution. Robust standard errors clustered at the headquarters' département level in parentheses. ${ }^{* * *} \mathrm{p}<0.01,{ }^{* *} \mathrm{p}<0.05,{ }^{*} \mathrm{p}<0.1$. 
Table 2 - Differential impact of distance to headquarters on the share of fixed-term contracts according to firm visibility at headquarters - IV estimates

\begin{tabular}{|c|c|c|c|c|c|}
\hline $\begin{array}{l}\text { Dep.var: } \\
\text { Share of fixed-term contracts }\end{array}$ & (1) & (2) & (3) & (4) & (5) \\
\hline Definition of self-centered/outward-looking & & \multicolumn{2}{|c|}{ Election turnout } & \multicolumn{2}{|c|}{ Charity giving } \\
\hline Département of Headquarters (HQ) & Full Sample & $\begin{array}{l}\text { Outward- } \\
\text { looking }\end{array}$ & Self-centered & Generous & Selfish \\
\hline Distance*High Visibility & $\begin{array}{l}-0.0045 \\
(0.0084)\end{array}$ & $\begin{array}{c}0.0160 \\
(0.0093)\end{array}$ & $\begin{array}{c}-0.0365 * * \\
(0.0149)\end{array}$ & $\begin{array}{c}0.0127 \\
(0.0101)\end{array}$ & $\begin{array}{c}-0.0299 * * \\
(0.0135)\end{array}$ \\
\hline Distance*Low Visibility & $\begin{array}{c}0.0089 \\
(0.0065)\end{array}$ & $\begin{array}{c}0.0174 * * \\
(0.0063)\end{array}$ & $\begin{array}{l}0.0125 \\
(0.0244)\end{array}$ & $\begin{array}{c}0.0116 \\
(0.0080)\end{array}$ & $\begin{array}{l}-0.0005 \\
(0.0158)\end{array}$ \\
\hline Control variables & yes & yes & yes & yes & yes \\
\hline Dist.*(HighVisib. - LowVisib.) - p-value & 0.052 & 0.838 & 0.098 & 0.908 & 0.198 \\
\hline Observations & 71,783 & 44,637 & 27,146 & 31,730 & 24,807 \\
\hline R-squared & 0.520 & 0.518 & 0.503 & 0.540 & 0.527 \\
\hline Angrist-Pischke F-test on Dist*HVisib & 821.19 & $1,192.29$ & 138.69 & 838.28 & 265.57 \\
\hline Angrist-Pischke F-test on Dist*LVisib & $1,111.48$ & $1,679.14$ & 296.76 & $3,618.54$ & 355.17 \\
\hline
\end{tabular}

Note - Models are estimated with 2SLS estimators. The dependent variable is the annual average share of fixed-term contracts in total hiring in percentage, as measured at the establishment level. Visibility dummies interacted with potential distance are used as instruments. Actual and potential distances to headquarters are measured in kilometers. Control variables include establishment age (6 classes) and size (7 classes), occupational and gender structure of the establishment workforce, firm size in the establishment's employment area (6 classes), 2-digit industry dummies, time-varying unemployment at the département level, year dummies, 6 dummies for firm size in the employment area of the headquarters interacted with distance, a dummy variable for large firms (as measured in the whole of France) where large is defined as the top $25 \%$ of the distribution, also interacted with distance, 4 dummies for missing establishment in a given quarter, headquarters and employment-area fixed effects and a dummy for high visibility. Visibility is measured as the share of the firm's employment in total employment of the local labor market where its headquarters are located. High visibility is captured by a dummy variable equal to 1 when the firm's share of local employment belongs to the top $25 \%$ of the distribution and 0 otherwise. Low visibility is equal to 1 if the firm belongs to the bottom $75 \%$ of the distribution and 0 otherwise. Election turnout is measured as the difference between the département-level turnout rates (in \% of registered voters) at the first round of the 2001 municipal elections and the 2000 referendum (on the 5-year - instead of 7-year - term for the President of the Republic). A firm is assumed to have headquarters located in an outward-looking département if its headquarters belong to the bottom half of the distribution of differential turnout rates. Symmetrically, firm headquarters are considered to be located in a self-centered département if they belong to the top half of the distribution. Charity giving is measured as the ratio of total charity donations in 1887 to département-level GDP. A firm is assumed to have headquarters located in a generous département if its headquarters belong to the top half of the charity giving distribution. Symmetrically, firm headquarters are considered to be located in a selfish département if its headquarters belong to the bottom half of the distribution.

Robust standard errors clustered at the headquarters' département level in parentheses. $* * * p<0.01, * * p<0.05, * \mathrm{p}<0.1$ 
Table 3 - Differential impact of distance to headquarters on the share of fixed-term contracts according to CEOs' place of living - IV estimates

\begin{tabular}{|c|c|c|c|c|c|}
\hline $\begin{array}{l}\text { Dep.var: } \\
\text { Share of fixed-term contracts }\end{array}$ & (1) & (2) & (3) & (4) & (5) \\
\hline $\begin{array}{l}\text { Definition of self-centered/outward- } \\
\text { looking }\end{array}$ & & \multicolumn{2}{|c|}{ Election turnout } & \multicolumn{2}{|c|}{ Charity giving } \\
\hline Département of Headquarters (HQ) & Full Sample & $\begin{array}{l}\text { Outward- } \\
\text { looking }\end{array}$ & Self-centered & Generous & Selfish \\
\hline Distance*CEO living at HQ & $\begin{array}{c}0.0077 \\
(0.0089)\end{array}$ & $\begin{array}{c}0.0190 * * \\
(0.0074)\end{array}$ & $\begin{array}{c}-0.0423 * * \\
(0.0180)\end{array}$ & $\begin{array}{c}0.0289 * * \\
(0.0125)\end{array}$ & $\begin{array}{l}-0.0477 * * \\
(0.0231)\end{array}$ \\
\hline Distance* CEO not living at HQ & $\begin{array}{c}0.0263 * * * \\
(0.0092)\end{array}$ & $\begin{array}{c}0.0259 * * \\
(0.0101)\end{array}$ & $\begin{array}{c}0.0261 \\
(0.0310)\end{array}$ & $\begin{array}{c}0.0212 \\
(0.0174)\end{array}$ & $\begin{array}{l}0.0483 * * \\
(0.0212)\end{array}$ \\
\hline Control variables & yes & yes & yes & yes & yes \\
\hline Dist*(Living - Not Living) - p-value & 0.236 & 0.669 & 0.060 & 0.737 & 0.011 \\
\hline Observations & 13,750 & 8,058 & 5,692 & 5,360 & 5,338 \\
\hline R-squared & 0.564 & 0.550 & 0.620 & 0.583 & 0.598 \\
\hline $\begin{array}{l}\text { Angrist-Pischke F-test on Dist*Living } \\
\text { Angrist-Pischke F-test on Dist*Not living }\end{array}$ & $\begin{array}{c}137.45 \\
66.44\end{array}$ & $\begin{array}{c}134.02 \\
98.92\end{array}$ & $\begin{array}{l}46.10 \\
11.12\end{array}$ & $\begin{array}{l}125.94 \\
83.46\end{array}$ & $\begin{array}{l}29.00 \\
20.13\end{array}$ \\
\hline
\end{tabular}

Note - Models are estimated with 2SLS estimators. The dependent variable is the annual average share of fixed-term contracts in total hiring in percentage, as measured at the establishment level. CEO's place of living dummies interacted with potential distance are used as instruments. Actual and potential distances to headquarters are measured in kilometers. Control variables include establishment age (6 classes) and size ( 7 classes), occupational and gender structure of the establishment workforce, firm size in the establishment's employment area (6 classes), 2-digit industry dummies, time-varying unemployment at the département level, year dummies, 4 dummies for missing establishment in a given quarter, headquarters and employment-area fixed effects and a dummy variable for CEO living at headquarters. A CEO is considered to live at the firm's headquarters if he or she lives within $50 \mathrm{~km}$ from the headquarters (this information can be constructed only since 2003 and for CEOs who are wage-and-salary employees of their firm). Election turnout is measured as the difference between the département-level turnout rates (in \% of registered voters) at the first round of the 2001 municipal elections and the 2000 referendum (on the 5 -year - instead of 7-year - term for the President of the Republic). A firm is assumed to have headquarters located in an outward-looking département if its headquarters belong to the bottom half of the distribution of differential turnout rates. Symmetrically, firm headquarters are considered to be located in a self-centered département if they belong to the top half of the distribution. Charity giving is measured as the ratio of total charity donations in 1887 to département-level GDP. A firm is assumed to have headquarters located in a generous département if its headquarters belong to the top half of the charity giving distribution. Symmetrically, firm headquarters are considered to be located in a selfish département if its headquarters belong to the bottom half of the distribution. Robust standard errors clustered at the headquarters' département level in parentheses. ${ }^{* * *} \mathrm{p}<0.01,{ }^{* *} \mathrm{p}<0.05,{ }^{*} \mathrm{p}<0.1$ 


\section{For online publication only}

\section{Appendix}

\section{A.1. Theoretical appendix}

Under the model's assumptions, the utility functions satisfy:

$$
U_{j}^{o}(\gamma)=\sum_{k=0}^{\infty}(1-\gamma)^{k}(1-w)-h^{o}-\sum_{k=0}^{\infty}(1-\gamma)^{k} \gamma\left(S_{j}+d^{o}\right)
$$

and

$$
U_{j}^{f}(\gamma)=\sum_{k=0}^{D-1}(1-\gamma)^{k}-w D-h^{f}
$$

We first show that they are both decreasing and convex in $\gamma$. Second, we characterize the risk level $\bar{\gamma}$ such that the CEO is indifferent between the two contracts and we demonstrate it is unique. Third, we show that it decreases with the adjustment costs on permanent contracts. We then consider a case where communities put pressure to hire workers on permanent rather than fixed-term contracts. Finally, we consider a case where risk distributions can shift with distance.

\section{A.1.1. Utility functions are decreasing and convex in $\gamma$}

Consider the utility derived by the CEO from a permanent contract:

$$
U_{j}^{o}(\gamma)=\frac{(1-w)}{\gamma}-c^{o}
$$

One gets

$$
\frac{\partial U_{j}^{o}(\gamma)}{\partial \gamma}=-\frac{(1-w)}{\gamma^{2}}<0
$$

and

$$
\frac{\partial^{2} U_{j}^{o}(\gamma)}{\partial \gamma^{2}}=\frac{2(1-w)}{\gamma^{3}}>0
$$


In the same way, the utility from a fixed-term contract reads:

$$
U_{j}^{f}(\gamma)=\sum_{k=0}^{D-1}(1-\gamma)^{k}-w D-h^{f}
$$

Then

$$
\frac{\partial U_{j}^{f}(\gamma)}{\partial \gamma}=-\sum_{k=0}^{D-1} k(1-\gamma)^{k-1}<0
$$

and

$$
\frac{\partial^{2} U_{j}^{f}(\gamma)}{\partial \gamma^{2}}=\sum_{k=0}^{D-1} k(k-1)(1-\gamma)^{k-2}>0
$$

\section{A.1.2. Characterization of the risk threshold $\bar{\gamma}$}

The risk threshold is defined by the indifference condition:

$$
U_{j}^{o}(\bar{\gamma})=U_{j}^{f}(\bar{\gamma})
$$

First notice that both utilities are strictly decreasing and convex in $\gamma$. Then remark that:

$$
\begin{gathered}
\lim _{\gamma \rightarrow O^{+}} U_{j}^{o}(\gamma) \rightarrow+\infty \\
\lim _{\gamma \rightarrow O^{+}} U_{j}^{f}(\gamma)=D(1-w)-h^{f}
\end{gathered}
$$

while

$$
\begin{aligned}
& \lim _{\gamma \rightarrow 1} U_{j}^{o}(\gamma)=1-w-c^{o} \\
& \lim _{\gamma \rightarrow 1} U_{j}^{f}(\gamma)=1-D w-h^{f}
\end{aligned}
$$

We only consider non-degenerate cases where $U_{j}^{f}(\gamma=1)>U_{j}^{o}(\gamma=1)$, that is where the fixed-term contracts are more profitable for the riskiest jobs. If it were not the case, permanent contracts would always be chosen. 
Notice that we do not assume that utilities are positive for $\gamma=1$ but that the loss, if any, is smaller under fixed-term contract than under permanent contract. Then, since both utilities are monotonic, decreasing and convex, and because:

$$
\lim _{\gamma \rightarrow O^{+}} U_{j}^{o}(\gamma)-U_{j}^{f}(\gamma) \rightarrow+\infty
$$

and

$$
\lim _{\gamma \rightarrow 1} U_{j}^{o}(\gamma)-U_{j}^{f}(\gamma)<0
$$

there is a unique risk threshold $\bar{\gamma}$. See Figure 1 for a graphical illustration.

\section{A.1.3. The effect of adjustment costs $c^{o}$ on contract choice}

We have just demonstrated that there is a unique risk threshold $\bar{\gamma}$. Moreover, remember that both utilities are monotonic, convex and that the difference $U_{j}^{o}(\gamma)-U_{j}^{f}(\gamma)$ is such that, for the lowest risk level, the utility from permanent contract is higher than the utility from fixedterm contracts:

$$
\lim _{\gamma \rightarrow O^{+}} U_{j}^{o}(\gamma)-U_{j}^{f}(\gamma) \rightarrow+\infty
$$

and, for the maximum risk level, the utility from permanent contracts is lower than the utility from fixed-term contracts:

$$
\lim _{\gamma \rightarrow 1} U_{j}^{o}(\gamma)-U_{j}^{f}(\gamma)<0
$$

Then, in the vicinity of $\bar{\gamma}$ :

$$
\left.\frac{\partial\left(U_{j}^{o}(\gamma)-U_{j}^{f}(\gamma)\right)}{\partial \gamma}\right|_{\gamma=\bar{\gamma}}<0
$$

Consider now the effect of a change in $c^{o}$. Differentiating $U_{j}^{o}(\bar{\gamma})=U_{j}^{f}(\bar{\gamma})$, one gets:

$$
\underbrace{\frac{\partial U_{j}^{o}(\bar{\gamma})}{\partial \bar{\gamma}} d \bar{\gamma}-\frac{\partial U_{j}^{f}(\bar{\gamma})}{\partial \bar{\gamma}} d \bar{\gamma}}_{<0}=d c^{o}
$$

and thus 


$$
\frac{d \bar{\gamma}}{d c^{o}}<0
$$

An increase in the adjustment costs of the permanent contract decreases the threshold. Hence, distance reduces the threshold.

\section{A.1.4. The effect of distance when communities put pressure to hire workers on permanent rather than fixed-term contracts}

If communities put pressure on CEOs to hire workers on permanent rather than fixedterm contracts, the adjustment cost paid upon hiring would be the sum of the writing cost and the social sanction, which in turn would decrease with distance in self-centered communities. Denoting the overall adjustment cost with $c^{f}$, we have:

$$
c^{f}=S^{f}+h^{f}
$$

with $d S^{f} / d \delta \leq 0$. By substituting $c^{f}$ for $h^{f}$ in all the equations of the main text, it is easy to show that all the statements concerning the outward-looking case made in the main text as well as in Appendices A.1.1 and A.1.2 still hold, since in this case $c^{f}$, like $h^{f}$, does not depend on distance. Similarly, denoting with $C$ the difference in overall adjustment costs between permanent and fixed-term contracts, that is $C=c^{o}-c^{f}$, and repeating the same proof as in Appendix A.1.3 but replacing $c^{o}$ with $C$, we obtain:

$$
\frac{d \bar{\gamma}}{d C}<0
$$

which implies:

$$
\frac{d L^{f}}{d C}=-f(\bar{\gamma}, \delta) \frac{d \bar{\gamma}}{d C}>0
$$

and

$$
\frac{d L^{f}}{d \delta}=-f(\bar{\gamma}, \delta) \frac{d \bar{\gamma}}{d C} \frac{d C}{d \delta}-\frac{\partial F(\gamma, \delta)}{\partial \delta} .
$$

The first term on the right-hand side is different from zero only in the self-centered case, where $C$ may vary as a function of $\delta$. In that case the sign of $d L^{f} / d \delta$ is ambiguous as long as $d C / d \delta<0$, that is as long as $d S / d \delta<d S^{f} / d \delta$, that is if the social sanction associated with dismissals decreases with distance more rapidly than the social sanction associated with hiring 
on fixed-term contracts. Note that this condition always holds if the latter is equal to a fraction of the former, that is if $S^{f}=\alpha S$, with $\alpha<1$.

\section{A.1.5 The effect of distance when there is a maximum level of profitable risk}

Consider that no job is profitable above a certain level, denoted with $\gamma^{\max }$. That is

$$
U_{j}^{f}\left(\gamma^{\max }\right)=0
$$

since we work under the assumption that $U_{j}^{f}(\gamma=1)>U_{j}^{o}(\gamma=1)$ (non-degenerate case). Notice that the adjustment costs related to permanent contracts have no effect on the maximum risk level, that is:

$$
\frac{\partial \gamma^{\max }}{\partial c^{o}}=0
$$

The share of permanent contracts reads:

$$
L^{o}=\frac{F(\bar{\gamma}, \delta)}{F\left(\gamma^{\max }, \delta\right)}
$$

where $F\left(\gamma^{\max }, \delta\right)$ stands for the probability that the job is profitable and therefore the worker is hired. Then the effect of adjustment costs for permanent contracts satisfies:

$$
\frac{\partial L^{o}}{\partial c^{o}}=\frac{f(\bar{\gamma}, \delta) F\left(\gamma^{\max }, \delta\right) \frac{d \bar{\gamma}}{d c^{o}}}{F\left(\gamma^{\max }, \delta\right)^{2}}<0
$$

We get the same effect as before: an increase in the adjustment costs for permanent contracts pushes the firm to be more selective and it decreases the risk threshold.

Looking at the effect of distance and allowing the distribution to shift with distance, on gets:

$$
\frac{\partial L^{o}}{\partial \delta}=\frac{f(\bar{\gamma}, \delta)}{F\left(\gamma^{\max }, \delta\right)} \frac{d \bar{\gamma}}{d S} \frac{d S}{d \delta}+\frac{F_{2}{ }^{\prime}(\bar{\gamma}, \delta) F\left(\gamma^{\max }, \delta\right)-F(\bar{\gamma}, \delta) F_{2}{ }^{\prime}\left(\gamma^{\max }, \delta\right)}{F\left(\gamma^{\max }, \delta\right)^{2}}
$$

When headquarters are located in an outward-looking community, social sanctions are independent of distance, $d S / d \delta=0$, so that the above expression can be rewritten as:

$$
\frac{\partial L^{o}}{\partial \delta}=\frac{F_{2}{ }^{\prime}(\bar{\gamma}, \delta) F\left(\gamma^{\max }, \delta\right)-F(\bar{\gamma}, \delta) F_{2}{ }^{\prime}\left(\gamma^{\max }, \delta\right)}{F\left(\gamma^{\max }, \delta\right)^{2}}
$$


The sign of the above expression is undetermined. Intuitively, when the distribution of risk shifts, more matches are unprofitable and thus both the number of permanent contracts and the number of fixed-term contracts change. However, $\partial L^{o} / \partial \delta<0$ in outward-looking communities if $F_{2}^{\prime}(\bar{\gamma}, \delta) F\left(\gamma^{\max }, \delta\right)<F(\bar{\gamma}, \delta) F_{2}{ }^{\prime}\left(\gamma^{\max }, \delta\right)$ which is a generalization of condition [1.1] when risk distribution can shift with distance. Since $F$ is non-negative and $F_{2}^{\prime}(\bar{\gamma}, \delta)<0$, this generalized condition may not hold only if $F^{\prime}\left(\gamma^{\max }, \delta\right)<0$, that is if, as distance increases, the probability that the worker is hired, and in large numbers the hiring rate, decreases. As shown in Table A10 in Appendix A.2, however, we find no evidence of this in our data. 


\section{A.2. Appendix Figures and Tables}

Figure A1 - Difference between municipal and national elections' turnout rates in French départements, by quartile of the distribution

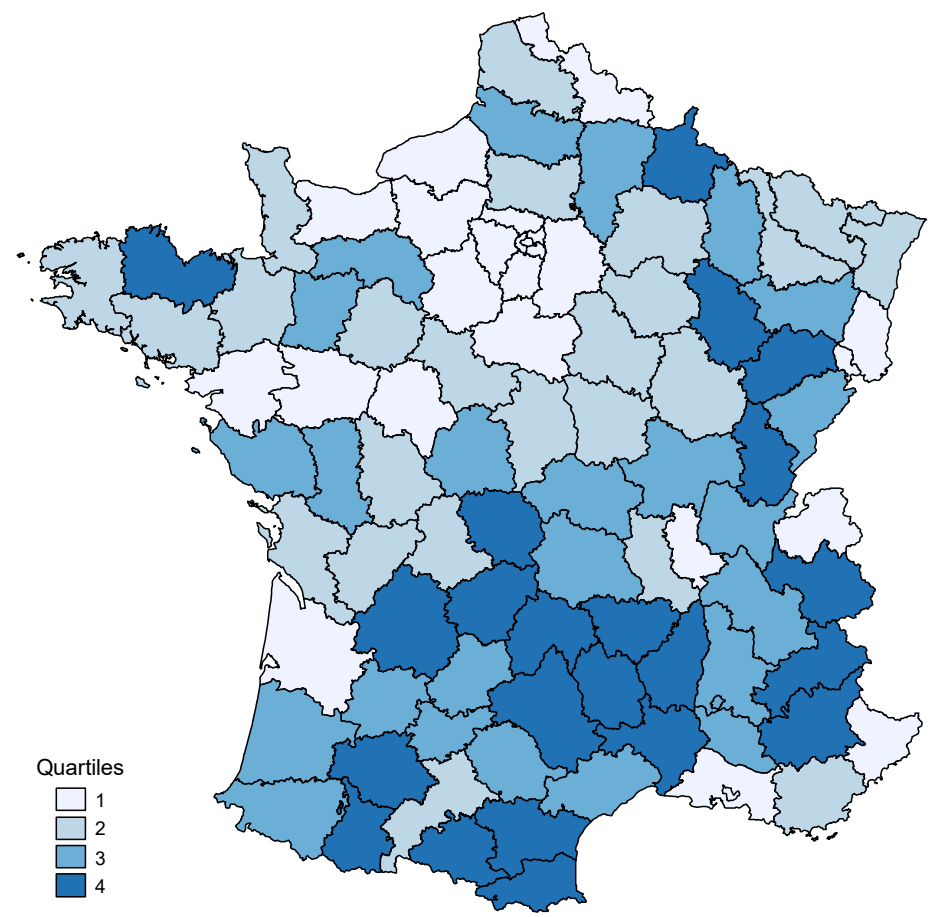

Note-Quartiles are computed on the cross-département distribution and ordered from the lowest to the highest.

Figure A2 - Number of headquarters in French employment areas, by quintile of the distribution

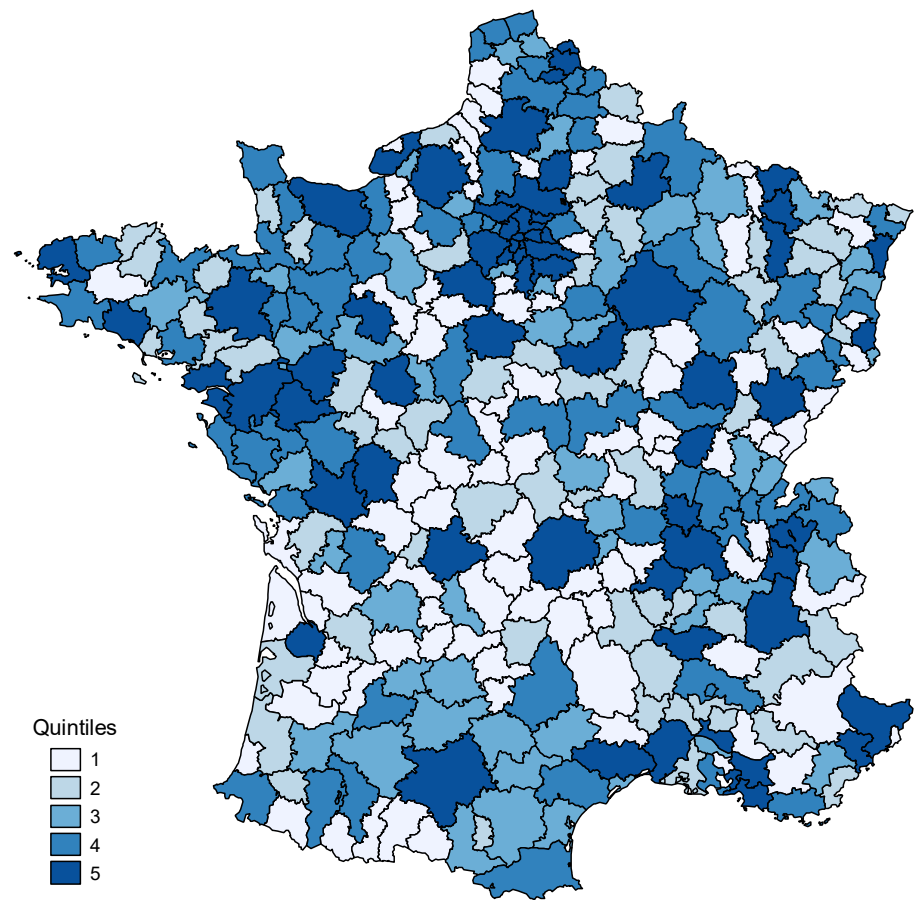

Note - Quintiles are ordered from the lowest to the highest. 
Table A1 - Correlation between distance to headquarters and the contribution to the firm market potential

\section{$C M P F$}

Potential Distance

$-0.0077(0.763)$
Actual Distance
$0.1498^{* * *}(0.000)$

$\overline{\text { Note - Variables in deviation from the firm average. The sample covers }}$ secondary establishments of business companies with at least 2 secondary establishments that were active between 1998 and 2009. pvalues in parentheses. Significance obtained adjusting for clustering at the firm level.

Table A2 - Firm's share of total employment in headquarters' employment area (\%)

\begin{tabular}{lc} 
Variables & \\
\hline & \\
Minimum & 0.000 \\
$1^{\text {st }}$ quartile & 0.016 \\
Median & 0.057 \\
$3^{\text {rd }}$ quartile & 0.186 \\
Maximum & 28.071 \\
& \\
\hline
\end{tabular}


Table A3 - Self-centeredness in the European Value Study (EVS) and Selfcenteredness based on Differential Election Turnout

\begin{tabular}{lccc}
\hline \hline $\begin{array}{l}\text { Dep.var: } \\
\text { Individual Self-centeredness in the EVS }\end{array}$ & $(1)$ & $(2)$ & $(3)$ \\
\multicolumn{2}{l}{$\begin{array}{l}\text { Panel A: Differential election turnout as measured } \\
\text { in the region of residence }\end{array}$} & \\
Differential election turnout & $0.0207^{* * *}$ & $0.0222^{* * *}$ & $0.0204^{* * *}$ \\
& $(0.0045)$ & $(0.0050)$ & $(0.0054)$ \\
& & & \\
Baseline controls & No & Yes & Yes \\
Extended controls & No & No & Yes \\
& & & \\
Observations & 1,492 & 1,348 & 1,315 \\
R-squared & 0.0050 & 0.0407 & 0.0601 \\
\hline
\end{tabular}

Panel B: Differential election turnout as measured in the department of residence at age 14

Differential election turnout

$\begin{array}{ccc}0.0197 * * & 0.0234^{* *} & 0.0187^{* *} \\ (0.0090) & (0.0092) & (0.0089)\end{array}$

Baseline controls

$\begin{array}{lll}\text { No } & \text { Yes } & \text { Yes } \\ \text { No } & \text { No } & \text { Yes }\end{array}$

Observations

$1,062 \quad 957$

943

R-squared

0.0058

0.0421

0.0641

Note - OLS estimates. The dependent variable is built using the following questions from the European Value Study: "Do you feel concerned about: (1) Immediate family, (2) People in the neighbourhood, (3) Human kind?" Answers range from 1 to 5 corresponding to "not at all", "not so much", "to a certain extent", "much", "very much". The dependent variable is the difference between the average score obtained when answering questions (1) and (2) and the score obtained when answering question (3). Baseline controls include gender, age ( 6 classes), education ( 3 classes), employment status ( 8 classes) and household income (12 classes). Extended controls include a dummy variable for whether the individual would vote if general elections would take place the day after and two dummy variables indicating how often the individual discusses political matters with friends. Election turnout is measured as the difference between the region/département-level turnout rates (in \% of registered voters) at the first round of the 2001 municipal elections and the 2000 referendum (on the 5-year - instead of 7-year - term for the President of the Republic). Observations in Panel B include only individuals who live in the region where they were born. Robust standard errors clustered at the regional level (Panel A) and at the département level (Panel B) in parentheses. ${ }^{* * *} \mathrm{p}<0.01,{ }^{* *} \mathrm{p}<0.05,{ }^{*} \mathrm{p}<0.1$ 
Table A4 - Distribution of département-level differential election turnout and charity giving across headquarters

\begin{tabular}{ll} 
Variables & \\
\hline $\begin{array}{l}\text { Difference (\% points) } \\
\text { turnout rates }\end{array}$ & \\
$\quad$ Minimum & 26.6 \\
$1^{\text {st }}$ quartile & 31.7 \\
Median & 36.3 \\
$3^{\text {rd }}$ quartile & 38.9 \\
Maximum & 51.1 \\
& \\
Ratio of total charity donations to GDP $(\%)$ & \\
Minimum & 0.047 \\
$1^{\text {st }}$ quartile & 0.126 \\
Median & 0.181 \\
$3^{\text {rd }}$ quartile & 0.260 \\
Maximum & 0.658 \\
\end{tabular}

Table A5 - Descriptive statistics of observations in our sample

\begin{tabular}{|c|c|c|c|c|c|}
\hline Variables & Mean & S.D. & Variables & Mean & S.D. \\
\hline \multirow{3}{*}{$\begin{array}{l}\text { Share of fixed-term contracts } \\
\text { (\% in total hiring) }\end{array}$} & \multirow[t]{3}{*}{57.50} & \multirow[t]{3}{*}{35.54} & \multicolumn{3}{|c|}{ Structure of the workforce ( $\%$ of plant employment) } \\
\hline & & & Managers & 10.71 & 16.35 \\
\hline & & & Technicians and supervisors & 21.55 & 19.96 \\
\hline \multirow{3}{*}{$\begin{array}{l}\text { Quarterly hiring rate } \\
\text { (\% in total employment) }\end{array}$} & \multirow[t]{3}{*}{13.01} & \multirow[t]{3}{*}{51.01} & Clerks & 29.92 & 32.41 \\
\hline & & & Blue collars & 37.82 & 34.17 \\
\hline & & & Women & 37.67 & 27.01 \\
\hline \multirow[t]{2}{*}{ Establishment size (headcount) } & \multirow[t]{2}{*}{111.39} & \multirow[t]{2}{*}{208.89} & & & \\
\hline & & & Industries $(\%)$ & & \\
\hline \multirow[t]{2}{*}{ Establishment age (years) } & \multirow[t]{2}{*}{8.82} & \multirow[t]{2}{*}{11.70} & Agriculture & 0.18 & 4.23 \\
\hline & & & Mining, Manufacturing, Energy & 20.58 & 40.43 \\
\hline \multirow{2}{*}{$\begin{array}{l}\text { Firm size in the employment } \\
\text { area of establishment }\end{array}$} & \multirow{2}{*}{254.39} & \multirow{2}{*}{628.77} & Construction & 9.59 & 29.44 \\
\hline & & & Services & 69.66 & 45.97 \\
\hline Local unemployment rate $(\%)$ & 8.19 & 1.95 & & & \\
\hline
\end{tabular}


Table A6 - Number of secondary establishments per firm by year

\begin{tabular}{|c|c|c|}
\hline & $\begin{array}{c}\text { (1) } \\
\begin{array}{c}\text { Establishments in our } \\
\text { sample }\end{array}\end{array}$ & $\begin{array}{c}(2) \\
\text { Establishments in } \\
\text { France }\end{array}$ \\
\hline $1^{\text {st }}$ quartile & 1 & 4 \\
\hline Median & 1 & 7 \\
\hline Mean & 3.0 & 23.6 \\
\hline $3^{\text {rd }}$ quartile & 3 & 15 \\
\hline Maximum & 231 & 2,808 \\
\hline
\end{tabular}

Table A7 - Distance to headquarters

\begin{tabular}{lcc}
\hline Variables & Mean & S.D. \\
\hline Distance in kilometers & & \\
Distance to HQ & 239.0 & 218.9 \\
Distance to HQ of the closest observation (within firm) & 97.0 & 148.8 \\
Distance to HQ of the median observation (within firm) & 172.5 & 184.1 \\
Distance to HQ of the farthest observation (within firm) & 262.5 & 245.2 \\
& \\
\hline Note - Observations are establishment-year couples. The median observation is the observation that \\
divides the within-firm distribution of distances in two equal parts. The mean (resp. standard \\
deviation) of the median, the closest and the farthest distances to HQ are computed on the \\
distribution of firms.
\end{tabular}


Table A8 - Impact of distance to headquarters on the share of fixed-term contracts - OLS estimates

\begin{tabular}{|c|c|c|c|c|c|}
\hline $\begin{array}{l}\text { Dep.var: } \\
\text { Share of fixed-term contracts }\end{array}$ & (1) & (2) & (3) & (4) & (5) \\
\hline \multicolumn{2}{|c|}{ Definition of self-centered/outward-looking } & \multicolumn{2}{|c|}{ Election turnout } & \multicolumn{2}{|c|}{ Charity giving } \\
\hline Département of Headquarters (HQ) & Full Sample & $\begin{array}{l}\text { Outward- } \\
\text { looking }\end{array}$ & Self-centered & Generous & Selfish \\
\hline Actual distance to HQ & $\begin{array}{l}-0.0021 \\
(0.0016)\end{array}$ & $\begin{array}{l}-0.0000 \\
(0.0014)\end{array}$ & $\begin{array}{c}-0.0073 * * * \\
(0.0019)\end{array}$ & $\begin{array}{c}0.0008 \\
(0.0009)\end{array}$ & $\begin{array}{c}-0.0088 * * * \\
(0.0018)\end{array}$ \\
\hline Control variables & yes & yes & yes & yes & yes \\
\hline Observations & 73,601 & 45,885 & 27,716 & 32,429 & 25,333 \\
\hline
\end{tabular}

Note - The dependent variable is the annual average share of fixed-term contracts in total hiring in percentage, as measured at the establishment level. Actual distance to headquarters is measured in kilometers. Control variables include establishment age (6 classes) and size (7 classes), occupational and gender structure of the establishment workforce, firm size in the establishment's employment area (6 classes), 2-digit industry dummies, time-varying unemployment at the département level, year dummies, 4 dummies for missing establishment in a given quarter and headquarters and employment-area fixed effects. Election turnout is measured as the difference between the département-level turnout rates (in $\%$ of registered voters) at the first round of the 2001 municipal elections and the 2000 referendum (on the 5-year - instead of 7-year - term for the President of the Republic). A firm is assumed to have headquarters located in an outward-looking département if its headquarters belong to the bottom half of the distribution of differential turnout rates. Symmetrically, firm headquarters are considered to be located in a self-centered département if they belong to the top half of the distribution. Charity giving is measured as the ratio of total charity donations in 1887 to département-level GDP. A firm is assumed to have headquarters located in a generous département if its headquarters belong to the top half of the charity giving distribution. Symmetrically, firm headquarters are considered to be located in a selfish département if its headquarters belong to the bottom half of the distribution. Robust standard errors clustered at the headquarters' département level in parentheses. $* * * \mathrm{p}<0.01, * *$ $\mathrm{p}<0.05, * \mathrm{p}<0.1$. 
Table A9 - Impact of distance to headquarters on the share of fixed-term contracts - IV estimates Instrument based on constant population

\begin{tabular}{|c|c|c|c|c|c|}
\hline $\begin{array}{l}\text { Dep.var: } \\
\text { Share of fixed-term contracts }\end{array}$ & (1) & (2) & (3) & (4) & (5) \\
\hline \multicolumn{2}{|c|}{ Definition of self-centered/outward-looking } & \multicolumn{2}{|c|}{ Election turnout } & \multicolumn{2}{|c|}{ Charity giving } \\
\hline Département of Headquarters (HQ) & Full Sample & $\begin{array}{l}\text { Outward- } \\
\text { looking }\end{array}$ & Self-centered & Generous & Selfish \\
\hline Actual distance to HQ & $\begin{array}{c}0.0031 \\
(0.0074)\end{array}$ & $\begin{array}{c}0.0120 * * \\
(0.0047)\end{array}$ & $\begin{array}{c}-0.0349 * * \\
(0.0156)\end{array}$ & $\begin{array}{c}0.0146^{* *} \\
(0.0055)\end{array}$ & $\begin{array}{c}-0.0395 * * * \\
(0.0128)\end{array}$ \\
\hline Control variables & yes & yes & yes & yes & yes \\
\hline Observations & 73,601 & 45,885 & 27,716 & 32,429 & 25,333 \\
\hline R-squared & 0.521 & 0.521 & 0.528 & 0.540 & 0.523 \\
\hline First stage coefficient on instrument & $\begin{array}{c}0.467 * * * \\
(0.085)\end{array}$ & $\begin{array}{l}0.401 * * \\
(0.151)\end{array}$ & $\begin{array}{l}0.441 * * * \\
(0.058)\end{array}$ & $\begin{array}{l}0.562 * * * \\
(0.090)\end{array}$ & $\begin{array}{l}0.445 * * * \\
(0.036)\end{array}$ \\
\hline
\end{tabular}

Note - Models are estimated with 2SLS estimators. The dependent variable is the annual average share of fixed-term contracts in total hiring in percentage, as measured at the establishment level. Potential distance, constructed assuming the same population in all employment areas, is used as an instrument. Actual and potential distances to headquarters are measured in kilometers. Control variables include establishment age (6 classes) and size (7 classes), occupational and gender structure of the establishment workforce, firm size in the establishment's employment area (6 classes), 2-digit industry dummies, time-varying unemployment at the département level, year dummies, 4 dummies for missing establishment in a given quarter and headquarters and employment-area fixed effects. Election turnout is measured as the difference between the départementlevel turnout rates (in \% of registered voters) at the first round of the 2001 municipal elections and the 2000 referendum (on the 5-year - instead of 7-year - term for the President of the Republic). A firm is assumed to have headquarters located in an outward-looking département if its headquarters belong to the bottom half of the distribution of differential turnout rates. Symmetrically, firm headquarters are considered to be located in a self-centered département if they belong to the top half of the distribution. Charity giving is measured as the ratio of total charity donations in 1887 to département-level GDP. A firm is assumed to have headquarters located in a generous département if its headquarters belong to the top half of the charity giving distribution. Symmetrically, firm headquarters are considered to be located in a selfish département if its headquarters belong to the bottom half of the distribution. Robust standard errors clustered at the headquarters' département level in parentheses. $* * * \mathrm{p}<0.01, * * \mathrm{p}<0.05, * \mathrm{p}<0.1$. 
Table A10 - Impact of distance to headquarters on the hiring rate - IV estimates

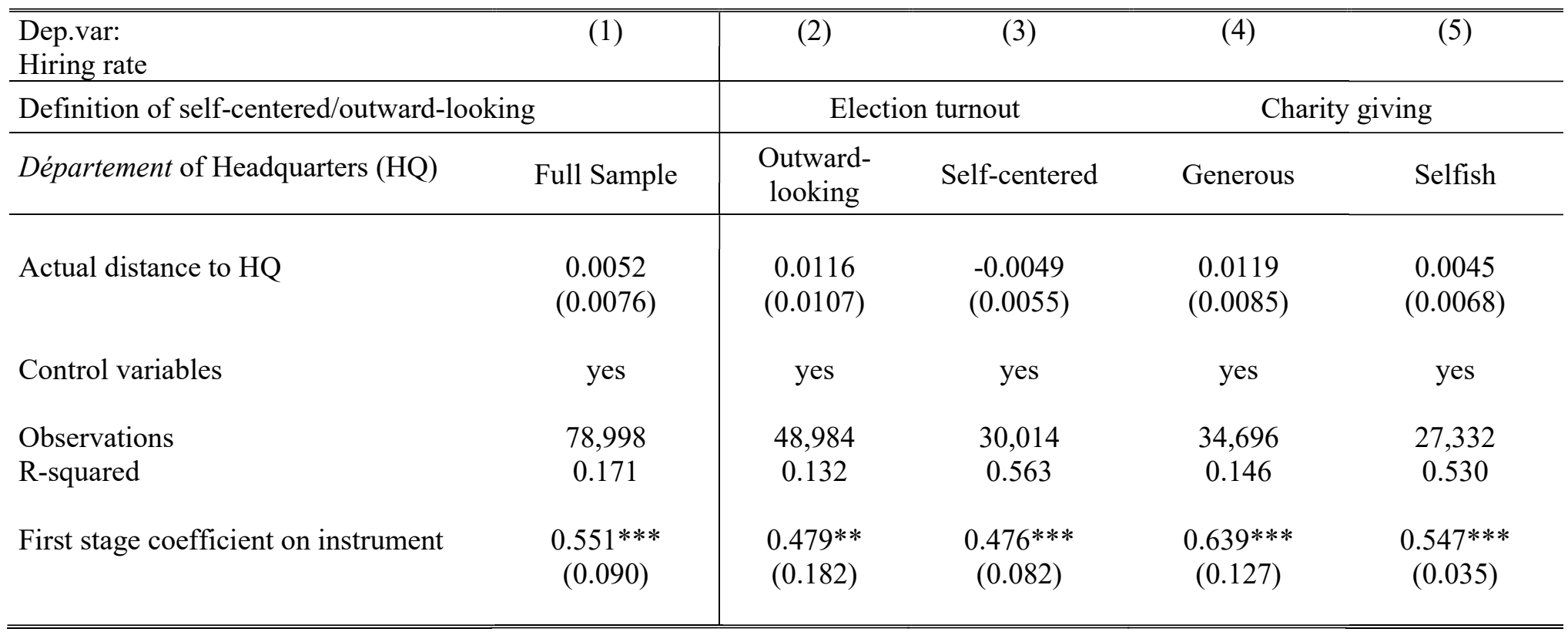

Note - Models are estimated with 2SLS estimators. The dependent variable is the yearly ratio of new hires to total employment, in percentage, as measured at the establishment level. Potential distance is used as an instrument. Actual and potential distances to headquarters are measured in kilometers. Control variables include establishment age (6 classes) and size (7 classes), occupational and gender structure of the establishment workforce, firm size in the establishment's employment area (6 classes), 2-digit industry dummies, time-varying unemployment at the département level, year dummies, 4 dummies for missing establishment in a given quarter and headquarters and employment-area fixed effects. Election turnout is measured as the difference between the département-level turnout rates (in \% of registered voters) at the first round of the 2001 municipal elections and the 2000 referendum (on the 5-year - instead of 7-year - term for the President of the Republic). A firm is assumed to have headquarters located in an outward-looking département if its headquarters belong to the bottom half of the distribution of differential turnout rates. Symmetrically, firm headquarters are considered to be located in a self-centered département if they belong to the top half of the distribution. Charity giving is measured as the ratio of total charity donations in 1887 to département-level GDP. A firm is assumed to have headquarters located in a generous département if its headquarters belong to the top half of the charity giving distribution. Symmetrically, firm headquarters are considered to be located in a selfish département if its headquarters belong to the bottom half of the distribution. Robust standard errors clustered at the headquarters' département level in parentheses. $* * * \mathrm{p}<0.01, * * \mathrm{p}<0.05, * \mathrm{p}<0.1$. 
Table A11 - Differential impact of distance to headquarters on the share of fixed-term contracts controlling for other firm characteristics interacted with distance - IV estimates

\begin{tabular}{|c|c|c|c|c|c|c|}
\hline $\begin{array}{l}\text { Dep.var: } \\
\text { Share of fixed-term contracts }\end{array}$ & (1) & (2) & (3) & (4) & $(5)$ & (6) \\
\hline Definition of self-centered/outward-looking & \multicolumn{3}{|c|}{ Election Turnout } & \multicolumn{3}{|c|}{ Charity giving } \\
\hline Distance*Outward-looking HQ & $\begin{array}{c}0.0160 * * * \\
(0.0042)\end{array}$ & $\begin{array}{l}0.0129 * * \\
(0.0063)\end{array}$ & $\begin{array}{c}0.0135 * * * \\
(0.0046)\end{array}$ & & & \\
\hline Distance* Self-centered HQ & $\begin{array}{c}-0.0319 * * * \\
(0.0071)\end{array}$ & $\begin{array}{c}-0.0389 * * * \\
(0.0103)\end{array}$ & $\begin{array}{c}-0.0385 * * * \\
(0.0096)\end{array}$ & & & \\
\hline Distance*Generous HQ & & & & $\begin{array}{c}0.0164 * * * \\
(0.0038)\end{array}$ & $\begin{array}{c}0.0117 \\
(0.0111)\end{array}$ & $\begin{array}{l}0.0171 * * \\
(0.0085)\end{array}$ \\
\hline Distance*Selfish HQ & & & & $\begin{array}{c}-0.0389 * * * \\
(0.0076)\end{array}$ & $\begin{array}{c}-0.0492 * * * \\
(0.0125)\end{array}$ & $\begin{array}{c}-0.0412 * * * \\
(0.0101)\end{array}$ \\
\hline Establishment controls & yes & yes & yes & yes & yes & yes \\
\hline Firm controls & no & yes & yes & no & yes & yes \\
\hline Distance*Firm controls: & & & & & & \\
\hline Distance*Age & no & yes & yes & no & yes & yes \\
\hline Distance*Occupation & no & yes & yes & no & yes & yes \\
\hline Distance*Size & no & yes & yes & no & yes & yes \\
\hline Distance*Labor Cost & no & yes & yes & no & yes & yes \\
\hline Distance*Industry & no & yes & no & no & yes & no \\
\hline Distance*Risk & no & no & yes & no & no & yes \\
\hline Distance*(Outward - Self-centered $)-p$-value & 0.000 & 0.000 & 0.000 & & & \\
\hline Distance*(Generous - Selfish $)-p$-value & & & & 0.000 & 0.000 & 0.000 \\
\hline Angrist-Pischke F-test on Dist*Outward-looking & 24.50 & 3715.00 & 783.52 & & & \\
\hline Angrist-Pischke F-test on Dist*Self-centered & 97.49 & 526.85 & 153.24 & & & \\
\hline Angrist-Pischke F-test on Dist*Generous & & & & 34.56 & 1387.97 & 589.75 \\
\hline Angrist-Pischke F-test on Dist*Selfish & & & & 56.82 & 218.32 & 102.20 \\
\hline Observations & 73,601 & 70,852 & 70,852 & 57,762 & 55,572 & 55,572 \\
\hline R-squared & 0.516 & 0.513 & 0.513 & 0.523 & 0.512 & 0.518 \\
\hline
\end{tabular}

Note - Models are estimated with 2SLS estimators. The dependent variable is the annual average share of fixed-term contracts in total hiring in percentage, as measured at the establishment level. Actual and potential distances to headquarters are measured in kilometers. Establishment controls include 
establishment age (6 classes) and size (7 classes), occupational and gender structure of the establishment workforce, firm size in the establishment's employment area (6 classes), 2-digit industry dummies, time-varying unemployment at the département level, year dummies, 4 dummies for missing establishment in a given quarter and headquarters and employment-area fixed effects. Firm controls include firm age, the occupational structure of the workforce, total firm size in France (dummy variable indicating whether the firm belongs to the top 25\% of the size distribution), log average daily labor cost per worker, the main 1-digit sector (in columns 2 and 5) and the standard deviation of firm employment growth within each 2-digit sector (columns 3 and 6). Election turnout is measured as the difference between the département-level turnout rates (in \% of registered voters) at the first round of the 2001 municipal elections and the 2000 referendum (on the 5-year - instead of 7-year - term for the President of the Republic). A firm is assumed to have headquarters located in an outward-looking département if its headquarters belong to the bottom half of the distribution of differential turnout rates. Symmetrically, firm headquarters are considered to be located in a self-centered département if they belong to the top half of the distribution. Charity giving is measured as the ratio of total charity donations in 1887 to département-level GDP. A firm is assumed to have headquarters located in a generous département if its headquarters belong to the top half of the charity giving distribution. Symmetrically, firm headquarters are considered to be located in a selfish département if its headquarters belong to the bottom half of the distribution. Self-centeredness/selfishness dummies and firm controls interacted with potential distance are used as instruments. Robust standard errors clustered at the headquarters' département level in parentheses. $* * * \mathrm{p}<0.01, * * \mathrm{p}<0.05, *$ $\mathrm{p}<0.1$. 
Table A12 - Differential impact of distance to headquarters on the share of fixedterm contracts controlling for rurality of the headquarters' département IV estimates

\begin{tabular}{|c|c|c|c|}
\hline $\begin{array}{l}\text { Dep.var: } \\
\text { Share of fixed-term contracts }\end{array}$ & (1) & (2) & (3) \\
\hline Definition of self-centered/outward-looking & \multicolumn{3}{|c|}{ Election Turnout } \\
\hline Distance*Outward-looking HQ & $\begin{array}{c}0.0160 * * * \\
(0.0042)\end{array}$ & $\begin{array}{l}0.0097 * * \\
(0.0048)\end{array}$ & $\begin{array}{c}0.0124 \\
(0.0089)\end{array}$ \\
\hline Distance* Self-centered HQ & $\begin{array}{l}-0.0319 * * * \\
(0.0071)\end{array}$ & $\begin{array}{c}-0.0296 * * * \\
(0.0084)\end{array}$ & $\begin{array}{c}-0.0346 * * * \\
(0.0113)\end{array}$ \\
\hline Baseline control variables & yes & yes & yes \\
\hline Rural HQ dummy & no & yes & yes \\
\hline Extended controls & no & no & yes \\
\hline Distance*Rural HQ & no & yes & yes \\
\hline Distance*Extended controls & no & no & yes \\
\hline Dist.*(Outward - Self-centered) - p-value & 0.000 & 0.000 & 0.011 \\
\hline Angrist-Pischke F-test on Dist*Outward-looking & 16.46 & 8.26 & 4.81 \\
\hline Angrist-Pischke F-test on Dist*Self-centered & 90.94 & 82.42 & 35.94 \\
\hline Observations & 73,601 & 73,601 & 73,601 \\
\hline R-squared & 0.516 & 0.514 & 0.514 \\
\hline
\end{tabular}

Note - Models are estimated with 2SLS estimators. The dependent variable is the annual average share of fixed-term contracts in total hiring in percentage, as measured at the establishment level. Actual and potential distances to headquarters are measured in kilometers. Baseline control variables include establishment age (6 classes) and size (7 classes), occupational and gender structure of the establishment workforce, firm size in the establishment's employment area (6 classes), 2-digit industry dummies, time-varying unemployment at the département level, year dummies, 4 dummies for missing establishment in a given quarter and headquarters and employment-area fixed effects. Election turnout is measured as the difference between the département-level turnout rates (in \% of registered voters) at the first round of the 2001 municipal elections and the 2000 referendum (on the 5-year - instead of 7-year - term for the President of the Republic). A firm is assumed to have headquarters located in an outward-looking département if its headquarters belong to the bottom half of the distribution of differential turnout rates. Symmetrically, firm headquarters are considered to be located in a self-centered département if they belong to the top half of the distribution. Rural HQ is a dummy variable equal to 1 if the département of the headquarters was defined as mostly rural in 2000 in the OECD Regional Database. Extended controls include the following variables measured at the level of the département of the headquarters: GDP per capita in 2005, the employment share of the tertiary sector (excluding public administration) in 2000, the time-varying unemployment rate and the share of individuals aged 16 or more who are not in education and have a diploma higher than upper secondary education (source: French Statistical Institute). Self-centeredness dummies and extended controls interacted with potential distance are used as instruments. Robust standard errors clustered at the headquarters' département level in parentheses. $* * * \mathrm{p}<0.01, * * \mathrm{p}<0.05, * \mathrm{p}<0.1$. 


\section{A.3. Distance Based on Social Ties}

The concept of distance that we have used so far is geographical (physical). We have assumed that, when headquarters are located in self-centered communities, as the distance between the establishment and its headquarters increases, social pressure decreases. The underlying assumption is that, as physical distance increases, social ties become looser, which tends to decrease social pressure and hence the adjustment cost associated with permanent contracts. To implement a more direct test of our theory, we use a concept of distance based on the intensity of social ties among communities. When doing so, we expect that, for headquarters located in self-centered communities, the share of fixed-term contracts in hiring will decrease with this measure of distance, i.e. when communities at headquarters and at plant are less strongly socially connected. Conversely, monitoring and asymmetric information problems should not vary with this measure of distance, except if the latter is strongly correlated with physical distance.

We take these predictions to the data by considering that an establishment is close to headquarters in terms of social ties when a high proportion of individuals living at headquarters were born in the geographical area of the establishment. We then estimate the following equation:

$$
L^{f}{ }_{j H t}=\beta_{0}+\beta_{1} \text { SocDist }_{j H t}+X_{j H t} \beta_{2}+D E_{j H}+D_{t}+D_{H}+\varepsilon_{j H t}
$$

where SocDist jHt $_{j}$ is our proxy of the social distance of establishment $j$ to the firm's headquarters and $D E_{j H}$ is a dummy variable for the département in which the establishment is located. With this specification, we expect to find $\beta_{1}<0$ for firms with headquarters located in self-centered communities if social pressure against dismissals is strong enough. To measure distance based on social ties, we use information from the French Labor Force Surveys for pre-sample years 1988 to 1997 . More specifically, we consider the proximity between headquarters located in municipality $\mathrm{A}$ and a given establishment located in municipality $B$ to be an increasing function of the average share of individuals living in the département of $\mathrm{A}$ who were born in the département of $\mathrm{B}$. The underlying assumption is that the greater this proportion, the more important the social and family ties across the populations of both départements. This suggests taking the inverse of proximity as a measure of distance. Yet, this is problematic since birthplace proximity is very concentrated around 0 (i.e. skewed) - see Figure A3. 
Figure A3 - Density of Birthplace proximity

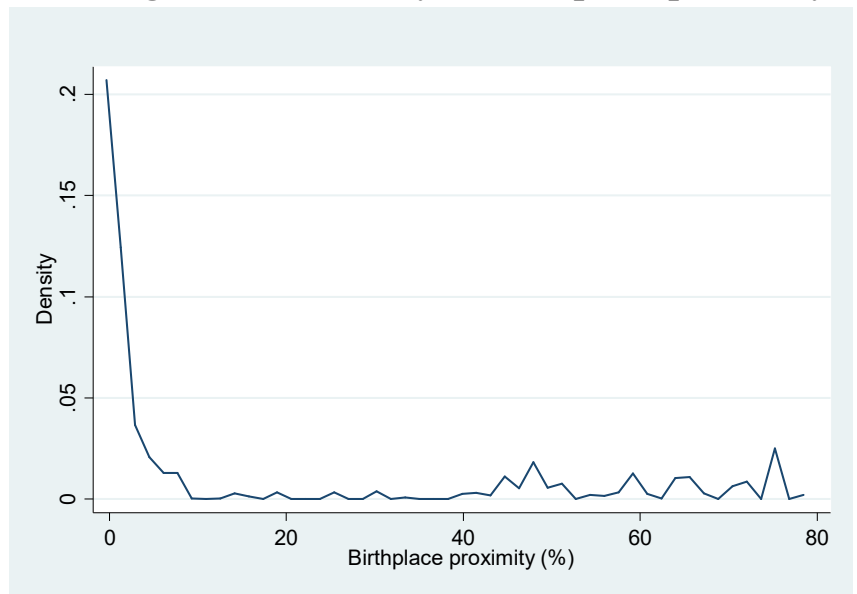

Note - Birthplace proximity is measured by the share of individuals living in the département of the headquarters who were born in the département of the establishment.

To overcome this problem, we rank all couples of départements from those with the highest (rank 1) to those with the lowest (rank 8,188) proximity. We define birthplace distance as the position in this ranking and use it as a measure of distance based on social ties. Unsurprisingly, birthplace distance turns out to be positively correlated with physical distance but this correlation is far from perfect (see Figure A4).

Figure A4 - Physical and Birthplace Distances

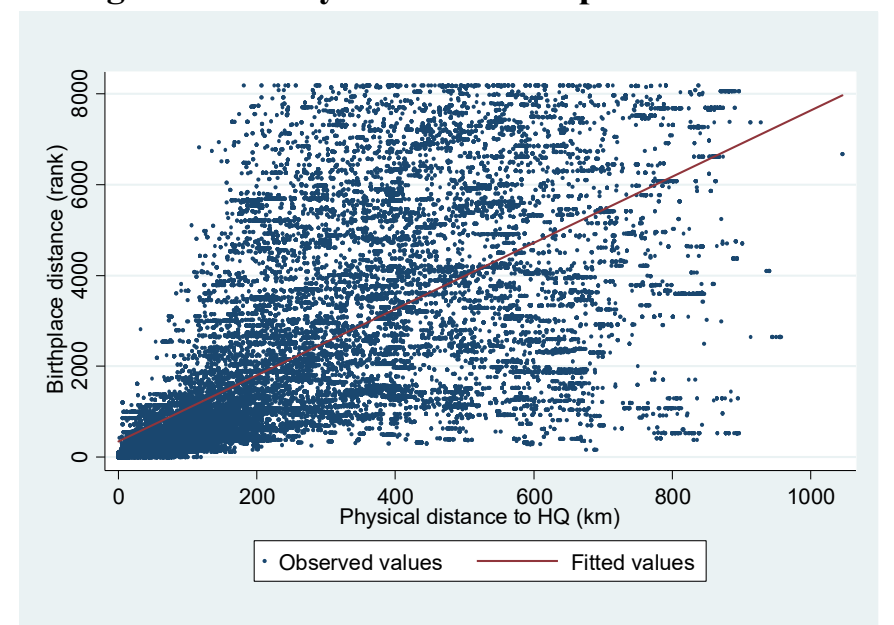

\begin{abstract}
Note - Physical distance is measured in kilometers. We define birthplace proximity as the share of individuals living in the département of the firm headquarters who were born in the département of the establishment. We rank all couples of departments from those with the highest (rank 1) to those with the lowest (rank 8,188) proximity. Our measure of birthplace distance is the position in this ranking.
\end{abstract}

The results obtained when estimating our social distance equation are presented in Table A13 below. When estimations are run on the full sample of observations, the impact of 
birthplace distance on the share of fixed-term contracts in hiring is negative although insignificant - see col (1). This is consistent with what we obtain when estimating the model separately for firms with headquarters located in self-centered and outward-looking départements. Whatever the measure of self-centeredness we use, the impact of birthplace distance is positive but insignificant for firms with headquarters in outward-looking départements - see col (2) and (4). This is not surprising since a measure of distance based on social ties is less relevant than physical distance as regards monitoring problems. However, especially in col (2), we cannot exclude that the large standard error is due to the weakness of the instrument. By contrast, this relationship is negative and significant for firms with headquarters in self-centered départements - see col (3) and (5). These findings confirm that, as social pressure decreases with birthplace distance, adjustment costs on permanent contracts tend to be higher for establishments located in areas that are more socially connected to the area of the headquarters. This translates into the fact that these establishments rely more on fixed-term contracts whenever their headquarters are located in a self-centered community. 
Table A13 - Impact of birthplace distance to headquarters on the share of fixed-term contracts - IV estimates

\begin{tabular}{|c|c|c|c|c|c|}
\hline $\begin{array}{l}\text { Dep.var: } \\
\text { Share of fixed-term contracts }\end{array}$ & (1) & (2) & (3) & (4) & (5) \\
\hline \multicolumn{2}{|c|}{ Definition of self-centered/outward-looking } & \multicolumn{2}{|c|}{ Election turnout } & \multicolumn{2}{|c|}{ Charity giving } \\
\hline Département of Headquarters (HQ) & Full Sample & $\begin{array}{l}\text { Outward- } \\
\text { looking }\end{array}$ & Self-centered & Generous & Selfish \\
\hline Actual birthplace distance to HQ & $\begin{array}{l}-0.0010 \\
(0.0028)\end{array}$ & $\begin{array}{c}0.0073 \\
(0.0115)\end{array}$ & $\begin{array}{l}-0.0044 * * \\
(0.0021)\end{array}$ & $\begin{array}{c}0.0025 \\
(0.0042)\end{array}$ & $\begin{array}{c}-0.0044 * * * \\
(0.0016)\end{array}$ \\
\hline Control variables & yes & yes & yes & yes & yes \\
\hline $\begin{array}{l}\text { Observations } \\
\text { R-squared }\end{array}$ & $\begin{array}{c}73,601 \\
0.514\end{array}$ & $\begin{array}{c}45,885 \\
0.457\end{array}$ & $\begin{array}{c}27,716 \\
0.501\end{array}$ & $\begin{array}{c}32,429 \\
0.525\end{array}$ & $\begin{array}{c}25,333 \\
0.498\end{array}$ \\
\hline First stage coefficient on instrument & $\begin{array}{l}0.123 * * * \\
(0.046)\end{array}$ & $\begin{array}{c}0.062 \\
(0.063)\end{array}$ & $\begin{array}{l}0.166 * * * \\
(0.036)\end{array}$ & $\begin{array}{l}0.103 * \\
(0.057)\end{array}$ & $\begin{array}{c}0.179 * * * \\
(0.048)\end{array}$ \\
\hline
\end{tabular}

Note - Models are estimated with 2SLS estimators. The dependent variable is the annual average share of fixed-term contracts in total hiring in percentage, as measured at the establishment level. We define birthplace proximity as the share of individuals living in the département of the firm headquarters who were born in the département of the establishment. We rank all couples of departments from those with the highest (rank 1 ) to those with the lowest (rank 8,188) proximity. Our measure of birthplace distance is the position in this ranking. Potential birthplace distance is used as an instrument. Control variables include establishment age (6 classes) and size ( 7 classes), occupational and gender structure of the establishment workforce, firm size in the establishment's employment area (6 classes), 2-digit industry dummies, time-varying unemployment at the département level, year dummies, 4 dummies for missing establishment in a given quarter and headquarters and département fixed effects. Election turnout is measured as the difference between the département-level turnout rates (in \% of registered voters) at the first round of the 2001 municipal elections and the 2000 referendum (on the 5-year - instead of 7-year - term for the President of the Republic). A firm is assumed to have headquarters located in an outward-looking département if its headquarters belong to the bottom half of the distribution of differential turnout rates. Symmetrically, firm headquarters are considered to be located in a self-centered département if they belong to the top half of the distribution. Charity giving is measured as the ratio of total charity donations in 1887 to département-level GDP. A firm is assumed to have headquarters located in a generous département if its headquarters belong to the top half of the charity giving distribution. Symmetrically, firm headquarters are considered to be located in a selfish département if its headquarters belong to the bottom half of the distribution. Robust standard errors clustered at the headquarters' département level in parentheses. ${ }^{* * *} \mathrm{p}<0.01,{ }^{*} \mathrm{p}<0.05, * \mathrm{p}<0.1$. 